\title{
EEG Correlates of Preparatory Orienting, Contextual Updating, and Inhibition of Sensory Processing in Left Spatial Neglect
}

\author{
(DStefano Lasaponara, ${ }^{1}$-Marianna D’Onofrio, ${ }^{1,2}{ }^{-}$Mario Pinto, ${ }^{1,2}$ Alessio Dragone, ${ }^{1,2}$ Dario Menicagli, ${ }^{3,6}$ \\ Domenica Bueti, ${ }^{4,5}{ }^{\circledR}$ Marzia De Lucia, ${ }^{5}$ Francesco Tomaiuolo, ${ }^{3}$ and Fabrizio Doricchi ${ }^{1,2}$ \\ ${ }^{1}$ Fondazione Santa Lucia, Centro Ricerche di Neuropsicologia, IRCCS, 00179 Roma, Italy, ${ }^{2}$ Dipartimento di Psicologia 39, Università degli Studi di Roma \\ "La Sapienza”, 00185 Roma, Italy, ${ }^{3}$ Auxilium Vitae, 56048 Volterra (Pisa), Italy, ${ }^{4}$ Area of Neuroscience, SISSA, 34136 Trieste, Italy, ${ }^{5} \mathrm{CHUV}$, Lausanne, 1011

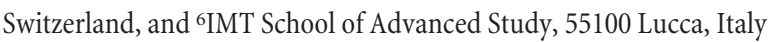

Studies with event-related potentials have highlighted deficits in the early phases of orienting to left visual targets in right-brain-damaged patients with left spatial neglect $(\mathrm{N}+)$. However, brain responses associated with preparatory orienting of attention, with target novelty and with the detection of a match/mismatch between expected and actual targets (contextual updating), have not been explored in $\mathrm{N}+$. Here in a study in healthy humans and brain-damaged patients of both sexes we demonstrate that frontal activity that reflects supramodal mechanisms of attentional orienting (Anterior Directing Attention Negativity, ADAN) is entirely spared in $\mathrm{N}+$. In contrast, posterior responses that mark the early phases of cued orienting (Early Directing Attention Negativity, EDAN) and the setting up of sensory facilitation over the visual cortex (Late Directing Attention Positivity, LDAP) are suppressed in $\mathrm{N}+$. This uncoupling is associated with damage of parietal-frontal white matter. $\mathrm{N}+$ also exhibit exaggerated novelty reaction to targets in the right side of space and reduced novelty reaction for those in the left side (P3a) together with impaired contextual updating (P3b) in the left space. Finally, we highlight a drop in the amplitude and latency of the P1 that over the left hemisphere signals the early blocking of sensory processing in the right space when targets occur in the left one: this identifies a new electrophysiological marker of the rightward attentional bias in $\mathrm{N}+$. The heterogeneous effects and spatial biases produced by localized brain damage on the different phases of attentional processing indicate relevant functional independence among their underlying neural mechanisms and improve the understanding of the spatial neglect syndrome.

Key words: attention; EDAN/ADAN/LDAP; ERPs; P1/N1; P300; spatial neglect

Significance Statement

Our investigation answers important questions: are the different components of preparatory orienting (EDAN, ADAN, LDAP) functionally independent in the healthy brain? Is preparatory orienting of attention spared in left spatial neglect? Does the sparing of preparatory orienting have an impact on deficits in reflexive orienting and in the assignment of behavioral relevance to the left space? We show that supramodal preparatory orienting in frontal areas is entirely spared in neglect patients though this does not counterbalance deficits in preparatory parietal-occipital activity, reflexive orienting, and contextual updating. This points at relevant functional dissociations among different components of attention and suggests that improving voluntary attention in $\mathrm{N}+$ might be behaviorally ineffective unless associated with stimulations boosting the response of posterior parietal-occipital areas.

\section{Introduction}

Right-brain damage (RBD) often produces a salient inability in orienting attention toward the left side of space, i.e., the "spatial

Received Sept. 27, 2017; revised Jan. 29, 2018; accepted Jan. 31, 2018.

Author contributions: S.L. and F.D. designed research; S.L., M.D., M.P., and A.D. performed research; S.L., M.D., D.M., D.B., M.D.L., and F.T. analyzed data; S.L., D.B., M.D.L., F.T., and F.D. wrote the paper.

This work was supported by Grants from the "Ministero della Salute" (Ricerca Finalizzata RF10.091) to F.D. and from the Fondazione Santa Lucia IRCCS to S.L. (Ricerca Corrente). We thank Paolo Bartolomeo, Michel Thiebaut de Schotten, and Gabriella Bottini for suggestions on the paper, and Brent D. Parsons for revising the English text.

The authors declare no competing financial interests. neglect" syndrome. Neglect is frequently associated with parietal and frontal lesions and the loss of crosstalk between these areas due to damage of underlying white-matter connections (Doricchi and Tomaiuolo, 2003; Mort et al., 2003; Thiebaut de Schotten

Correspondence should be addressed to either of the following: Dr. Fabrizio Doricchi, Dipartimento di Psicologia 39, Università degli Studi di Roma "La Sapienza", Via dei Marsi 78, 00185 Roma, Italy, E-mail: fabrizio.doricchi@uniroma1.it; or Dr. Stefano Lasaponara, Fondazione Santa Lucia, Centro Ricerche di Neuropsicologia, IRCCS, Via Ardeatina 306, 00179 Roma, Italy, E-mail: lasaponara.stefano@gmail.com.

DOI:10.1523/JNEUROSCI.2817-17.2018

Copyright $\odot 2018$ the authors $\quad 0270-6474 / 18 / 383792-17 \$ 15.00 / 0$ 
Table 1. Clinical and demographic group data of RBD patients with left spatial neglect $(\mathrm{N}+)$, without left spatial neglect $(\mathrm{N}-$ ), and healthy controls $(\mathrm{HCs})$. Maximal scores for each test are reported in parenthesis

\begin{tabular}{|c|c|c|c|c|c|c|c|c|c|c|c|c|c|}
\hline \multirow[b]{2}{*}{ Patient case } & \multirow[b]{2}{*}{ Sex } & \multirow[b]{2}{*}{ Age, y } & \multirow{2}{*}{$\begin{array}{l}\text { Stroke } \\
\text { onset, } \\
\text { months }\end{array}$} & \multirow{2}{*}{$\begin{array}{l}\text { Line bisection } \\
\text { ( } 200 \mathrm{~mm} \text { ) rightward } \\
\text { deviation, } \mathrm{mm}\end{array}$} & \multicolumn{2}{|c|}{ Letter cancellation } & \multicolumn{2}{|c|}{ Line cancellation } & \multicolumn{2}{|c|}{ Star cancellation } & \multirow{2}{*}{$\begin{array}{l}\text { Sentence reading } \\
\text { test }(\max =6)\end{array}$} & \multicolumn{2}{|c|}{$\begin{array}{l}\text { Wundt-Jastrow } \\
\text { illusion (unexpected } \\
\text { responses) }\end{array}$} \\
\hline & & & & & Left & Right & Left & Right & Left & Right & & Left & Right \\
\hline \multicolumn{14}{|c|}{$(\mathrm{N}-), n=13$} \\
\hline Mean & $M=10$ & 61.9 & 1.3 & -0.25 & $51(53)$ & $48.6(51)$ & $10.9(11)$ & $10(10)$ & $26.2(27)$ & $25.7(27)$ & $5.9(6)$ & $0.2(20)$ & $0.1(20)$ \\
\hline (SD) & $F=3$ & 9.3 & 0.47 & 2.8 & 2.7 & 5.5 & 0.2 & 0 & 1 & 1.8 & 0.2 & 0.5 & 0.5 \\
\hline \multicolumn{14}{|l|}{$(\mathrm{N}+), n=12$} \\
\hline Mean & $M=8$ & 62.6 & 1.7 & 23.2 & $19(53)$ & $28(51)$ & $6.2(11)$ & $8.3(10)$ & $9.2(27)$ & $15.5(27)$ & $3.1(6)$ & $10.1(20)$ & $0.5(20)$ \\
\hline (SD) & $F=4$ & 10.4 & 0.36 & 19.9 & 20.5 & 21.2 & 5.1 & 2.4 & 11.1 & 8.6 & 2.9 & 8.1 & 1.1 \\
\hline \multirow[t]{2}{*}{$\mathrm{HC}, n=15$} & $M=8$ & 53.2 & & & & & & & & & & & \\
\hline & $F=7$ & 11.1 & & & & & & & & & & & \\
\hline
\end{tabular}

et al., 2005; Bartolomeo et al., 2007; Doricchi et al., 2008; Verdon et al., 2010; Thiebaut de Schotten et al., 2011). Past investigations have well established that in patients with neglect $(\mathrm{N}+)$ the $\mathrm{N} 1$ and P2 event-related potential (ERP) components evoked by targets in the left side of space show a relative increase in latency and reduction in amplitude (Verleger et al., 1996; Deouell et al., 2000; Di Russo et al., 2008). Both of these components mark early phases in attentional processing. The $\mathrm{N} 1$ originates in the intraparietal sulcus and reflects facilitation of sensory processing at attended spatial positions (Hillyard et al., 1998). The $\mathrm{P} 2$ reflects attentional reactivation of the occipital cortex (Di Russo et al., 2008). Nonetheless, other important components of orienting remain totally unexplored in $\mathrm{N}+$. In healthy humans, voluntary orienting of attention guided by symbolic spatial cues, e.g., an arrow, presented at central fixation is associated with three preparatory ERP components that have higher amplitude over the hemisphere contralateral to the expected target location (Eimer, 2014). The first component is an "Early Directing Attention Negativity" (EDAN) that occurs 200-400 ms post-cue in parietal-occipital areas. This component is interpreted as marking the early phases of the attentional shift toward the lateral position of the target (Harter et al., 1989; Nobre et al., 2000) or, alternatively, the spatial selection of task-relevant features in central visual cues that guide lateral shifts of attention (Van Velzen and Eimer, 2003). The second component is an "Anterior Directing Attention Negativity" (ADAN) that reflect supramodal mechanisms of attentional engagement in frontal areas and occurs 500-900 ms post-cue (Eimer et al., 2002; Praamstra et al., 2005). The third component is a "Late Directing Attention Positivity" (LDAP; Harter et al., 1989; Hopf and Mangun, 2000) that marks the setting-up of facilitatory effects in posterior visual areas $500-1000 \mathrm{~ms}$ post-cue. No study of these components is available in $\mathrm{N}+$. This gap is relevant because, based on behavioral measures, voluntary orienting of attention is usually considered relatively spared in $\mathrm{N}+$ and exploited for rehabilitation purposes (for review, see Natale et al., 2005). In addition, studying the effects of localized brain damage can provide clues on the mutual functional reliance of these components in the normal brain, i.e., whether each of them can be independently suppressed by brain damage. The first aim of our study was to gain new insights in these issues.

Another relevant and poorly explored aspect of spatial neglect is whether the drop in the interest of $\mathrm{N}+$ for events in the left space is also linked to defective evaluation of the novelty and the probabilistic distribution of sensory events in that space, i.e., contextual updating. In the healthy brain the P3a and P3b components reflect novelty detection and the updating of probabilistic occurrence of a stimulus based on its past exposures, respectively (Polich, 2007). The P3a is generated in frontal and cingulate do- paminergic structures (Daffner et al., 2000, 2003; Polich, 2007) whereas the $\mathrm{P} 3 \mathrm{~b}$ is generated in temporal-parietal areas innervated by norepinephrine and marks the categorization of stimuli as a function of their match or mismatch to expected ones (Polich, 2007; Doricchi et al., 2010; Macaluso and Doricchi, 2013). Past studies in $\mathrm{N}+$ have demonstrated an increment in the latency and a reduction in the amplitude of the P300 elicited by stimuli in the left space (Lhermitte et al., 1985; Verleger et al., 1996; Saevarsson et al., 2012). Nonetheless, despite the clear distinction between the functions played by the P3a and P3b no study has specifically explored these components in $\mathrm{N}+$. The second main aim of our investigation was to fill this gap.

Finally, we exploited recent ERP findings in healthy humans to identify a new marker of the pathological rightward attentional bias of $\mathrm{N}+$ in a specific modification of the $\mathrm{P} 1$ component that originates from the joint activity of areas $\mathrm{V} 3 \mathrm{a}$ and $\mathrm{V} 4$ and that reflects suppression of processing at non-attended spatial locations (Hillyard et al., 1998). Slagter et al. (2016) showed that validly cued visual targets evoke a larger P1 over the hemisphere contralateral to the nonstimulated side of space, thus marking the target-related blocking of sensory processing in this side of space. Here we verified whether the rightward bias of $\mathrm{N}+$ is matched with reduced blocking of sensory input in this side of space, which is with reduced amplitude of the P1 over the left hemisphere when expected targets are presented in the left side of space.

\section{Materials and Methods Participants}

Patients were consecutively screened for inclusion in the study on admission for physical and neuropsychological rehabilitation at the Fondazione Santa Lucia IRCCS (Rome). Patients with bilateral strokes, signs of dementia, or history of previous neurological illness were excluded. Two groups of patients completed the experimental protocol and were included in final data analyses: $12 \mathrm{RBD}$ patients with left spatial neglect $(\mathrm{N}+)$ and 13 RBD patients without neglect $(\mathrm{N}-)$. In addition, 15 age-matched healthy participants were tested as controls (C). Patients and participants were all right-handed and had normal or corrected-to-normal visual acuity. At the time of clinical and experimental examination, all patients were free from confusion and from temporal or spatial disorientation. Visual fields were tested with standard kinetic Goldmann perimetry. All patients had intact visual fields, with the exception of one $\mathrm{N}+$ patient who suffered restriction of the left inferior quadrant with sparing of $10^{\circ}$ around central fixation. $\mathrm{N}+$ and $\mathrm{N}-$ patients did not differ in time elapsed from stroke onset $\left(F_{(1,11)}=3, p=0.23\right.$; mean $\left.=46 \mathrm{~d}\right)$. Age was equivalent among $\mathrm{N}+, \mathrm{N}-$, and $\mathrm{C}\left(F_{(2,22)}=2.6, p=0.32\right.$; mean age: $\mathrm{C}=53.2 ; \mathrm{N}+=62.6$; $\mathrm{N}-=61.9$ years $)$. Clinical and demographic data are reported in Table 1 . Patients and controls gave their informed consent for participating in the study that was approved by the Institutional Ethical Committee of the Fondazione Santa Lucia IRCCS. 


\section{Clinical assessment of neglect}

Unilateral neglect was assessed with a battery composed of six standardized tests:

(1) Line bisection: the task requires the bisection of five horizontal 200 $\mathrm{mm}$ lines. Each line is separately presented at the center of a horizontally oriented A3 paper sheet. Rightward deviations from the true line center are scored as positive deviations (in $\mathrm{mm}$ ) and leftward deviations as negative ones. The cutoff score for spatial neglect is $6.5 \mathrm{~mm}$ (Azouvi et al., 2002).

(2) Letter cancellation (Diller et al., 1974): the task requires the cancellation of target capital letters presented on a horizontally oriented A3 paper sheet. Letters are arranged in six rows. In each row, target letters $(\mathrm{H})$ are intermixed with filler letters (total score range $0-104 ; 0-53$ on the left side, $0-51$ on the right side). The presence of neglect is indicated by a difference of four or more omissions between the contralesional and ipsilesional side of the sheet.

(3) Line cancellation (Albert, 1973): the task requires the cancellation of short line segments that are arranged in scattered order and random orientation on an $\mathrm{A} 3$ paper sheet (total score range $0-21 ; 0-11$ on the left side, $0-10$ on the right side). Neglect is indicated by a difference of one or more omissions between the contralesional and ipsilesional side of the sheet.

(4) Star cancellation (Halligan et al., 1990): the task requires the cancellation of small stars that are presented on a A3 paper sheet interspersed with 52 large stars, 13 letters, and 10 short words that act as distracters (total score $=54: 27$ on the left side and 27 on the right side). Neglect is indicated by a difference of three or more omissions between the contralesional and ipsilesional side of the sheet.

(5) Sentence reading test (Pizzamiglio et al., 1992): the score is the number of sentences red without omissions/errors (score range 0-6). One or more omissions/errors in reading the initial part of the sentence or of the words composing the sentence indicates left spatial neglect.

(6) Wundt-Jastrow area illusion test (Massironi et al., 1988): the score is the frequency of missed optical illusion when the two fans are oriented toward the contralesional or the ipsilesional side of space (score range $0-20$ in both cases). The performance is considered pathologically biased when the contralesional versus ipsilesional difference in the frequency of missed illusions is $>2$.

Patients who failed on at least two of the six tests were classified as suffering left spatial neglect. Clinical and demographic data of the $\mathrm{N}+$, $\mathrm{N}-$, and $\mathrm{C}$ groups are reported in Table 1.

\section{Lesion mapping}

Individual 1.5 T MRI scans were corrected for interindividual differences in brain size and brain volume orientation, using a transformation into the standardized MNI space using the software REGISTER (http://www. bic.mni.mcgill.ca/ServicesSoftwareVisualization/Register). This program uses more than five neuroanatomical landmarks to match individual brain volumes to the Colin-MNI brain. Selection of damaged area in individual MRI scans registered in MNI space was made through the DISPLAY mousebrush (http://www.bic.mni.mcgill.ca/software/Display/Display.html) that allows coloring selected voxels. This operation is accompanied by the simultaneous $3 \mathrm{D}$ view of brain volumes and the visualization of the movements of the mouse-brush within the sagittal, axial, and coronal planes, thus optimizing the identification of lesion landmarks. The probability maps of $\mathrm{N}+$ and $\mathrm{N}-$ groups are reported in Figure 1. In each experimental group, the MNI coordinates of the centroids of areas of maximal lesion overlap were defined using the command DISPLAY. To check whether peaks of lesion overlap highlighted in the $\mathrm{N}+$ versus $\mathrm{N}$ - subtraction encroached upon white-matter pathways, we used the diffusion tensor imaging-based atlases by Thiebaut de Schotten et al. (2011) and by Oishi et al. (2008). White-matter pathways were visualized using MRICron software (Rorden et al., 2007). Using Tractotron software (Thiebaut de Schotten et al., 2014; BCBtoolkit, http://www.brainconnectivitybehaviour.eu).

\section{Procedure and stimuli}

Participants were tested with the head comfortably blocked by a chin rest, in a dimly lit, sound-attenuated, electrically shielded room. Stimuli were presented on a video monitor (22 inch) at a viewing distance of $57.5 \mathrm{~cm}$.
Presentation of stimuli and recording of manual reaction times (RTs) was performed with E-prime software (Schneider et al., 2002). The experiment included four experimental sessions that were run on different days and were separated by a 1-2 d interval. A total number of 280 "Valid" trials (140 with the target in the left side of space and 140 with the target in the right side), 120 "Invalid" trials (60 left side, 60 right side), 160 "Neutral" ( 80 left side, 80 right side), and 48 "Catch" trials (16 cue left side, 16 cue right side, 16 neutral cues) were administered during the four experimental sessions. An equal number of 152 (70 Valid, 30 Invalid, 40 Neutral, and 12 Catch) trials were delivered in each session.

Each trial started with the presentation of a central fixation cross (size: $1^{\circ} \times 1^{\circ}$ ) and two lateral boxes (size: $1^{\circ} \times 1^{\circ}$ ), one centered $4.5^{\circ}$ to the left and the other $4.5^{\circ}$ to the right of central fixation. This "Fixation" period lasted $800-1000 \mathrm{~ms}$ (uniform distribution) and was followed by a "Cue" period, lasting between 1800 and $2400 \mathrm{~ms}$ (uniform distribution). This relatively extended cue period was adopted to counteract any potential slowing in the engagement of attention in patients with RBD (Husain and Rorden, 2003) and favor the full deployment of spatial attention. In directional valid and invalid trials, at the beginning of the Cue period an arrow-cue pointing to the left or the right box was presented at central fixation. In this case, participants were asked to pay attention to the box indicated by the cue. In nondirectional neutral trials, the arrow was replaced by an "=" symbol. In this case, participants were instructed that the symbol indicated no specific side of space and that they had to wait for target presentation without paying attention to one of the two lateral boxes. At the end of the Cue period, a target-asterisk (size: $0.6^{\circ} \times 0.6^{\circ}$ ) was presented for $300 \mathrm{~ms}$ at the center of one of the two boxes, with the central cue remaining on until target disappearance. Once the target and the cue disappeared, $2 \mathrm{~s}$ were allowed for response ("Response" period). In each trial, participants were asked to detect the target by pressing a central button with their right index finger as soon as possible and to withhold response when no target was presented (catch trials). On Valid trials, the target was presented in the box cued by the arrow. On Invalid trials, the target was presented in the box opposed to that cued by the arrow. It is worth noting that directional cues presented during Valid and Invalid trials were statistically informative of target location, because $70 \%$ of trials were Valid (280/400) and 30\% were Invalid (120/400). On Neutral trials with nondirectional cues, the target was presented with equal probability in one of the two boxes. The experiment also included directional-Catch and nondirectional-Neutral Catch trials with no target presentation. Central fixation, boxes, and targets were in white, cues in yellow. All stimuli were presented on a black background (Fig. 2). Participants were required to hold their gaze on central fixation throughout the trial and try not to blink during the cue and target period. Eye movements were monitored with an infrared eye tracker (Tobii X120, sampling rate $8.3 \mathrm{~ms}$ ). The eye tracker allows the continuous and instantaneous check of gaze position within a notification window in the screen used by the experimenter. Using this window, the experimenter triggered the start of each trial only when the gaze of the participant was within an area of $1^{\circ}$ around the central fixation point.

\section{EEG recording and preprocessing}

The EEG was recorded using a Brain Vision system from 64 electrodes placed according to the 10-10 system montage. All scalp channels were online referenced to the left mastoid (M1). Horizontal eye movements were monitored with a bipolar recording from electrodes at the left and right outer canthi. Blinks and vertical eye movements were recorded with an electrode below the left eye, which was referenced to site Fp1. The EEG from each electrode site was digitized at $250 \mathrm{~Hz}$ with an amplifier bandpass of $0.01-60 \mathrm{~Hz}$, including a $50 \mathrm{~Hz}$ notch filter, and was stored for off-line averaging. Continuous EEG was recalculated against the average reference and successively segmented in epochs lasting $2000 \mathrm{~ms}$ for cuelocked analysis and $1000 \mathrm{~ms}$ for target-locked analysis. In both cases 200 $\mathrm{ms}$ before the events were used as baseline. Before computerized artifact rejection, ocular correction was performed accordingly to the Gratton and Coles algorithm (Gratton et al., 1983). Artifact rejection was performed before signal averaging to discard epochs in which deviations in eye position, blinks, or amplifier-blocking occurred. All epochs in which EOG amplitudes and EEG amplitudes were $> \pm 60 \mathrm{mV}$ were excluded 
from further analysis. On average, $4.9,3.8$, and $4.2 \%$ of the trials were rejected for violating these artifact criteria in the healthy subject, $\mathrm{N}-$ and $\mathrm{N}+$ group, respectively. Notwithstanding this relatively low number of epochs discarded due to artifact in the EEG, the general high number of missed target in the $\mathrm{N}+$ group (up to $62 \%$ of missed Invalid targets in the left side of space, see Results) and the marked interindividual variance in the hit-rate as a function of target type (Valid, Neutral, and Invalid) in $\mathrm{N}+$ and $\mathrm{N}-$ patients, precluded the possibility of running separate ERP analyses target- for hit and missed targets.

\section{Statistical analyses}

\section{Clinical and demographical data}

To analyze clinical performance in the two groups of patients, individual scores of Line bisection and Sentence reading test were compared through an unpaired two-tailed $t$ test with $p$ level set to 0.05 . Individual scores from Letter cancellation, Line cancellation, Star Cancellation, and the Wundt-Jastrow Area Illusion task were entered in a Group (N-, $\mathrm{N}-$ ) $\times$ Target Side (left, right) repeated-measures ANOVA.

\section{Lesion analyses}

First, lesion volume of the two groups of patients was compared through a one-way repeated-measure ANOVA. Second, Descriptive and inferential statistical comparisons of lesion mapping were run by subtracting the probability map of the $\mathrm{N}-$ group from that of the $\mathrm{N}+$ group and by comparing, with Fisher exact test, the frequency of damage occurrence at the centroids of the areas of maximal lesion overlap. Lesion probability maps resulting from this subtraction and the corresponding MNI coordinates of centroids of lesion overlaps are reported in Figure 1.

Successively, we evaluated individual probability of disconnection of white-matter pathways that included the peaks of lesion overlap highlighted in the $\mathrm{N}+$ versus $\mathrm{N}-$ subtraction. Individual probabilities were first entered in one-way $\mathrm{N}+$ versus $\mathrm{N}$ - repeated-measures ANOVA. In a second step, this ANOVA was run again using lesion volume as a covariate (ANCOVA).

\section{Behavioral performance and RTs}

Omissions. Due to the different frequency of Valid, Neutral, and Invalid trials, individual percentage of omissions were initially submitted to arcsine transformation (Sheskin, 2003). Percentages were entered in a Group $(\mathrm{C}, \mathrm{N}-$, and $\mathrm{N}+) \times$ Trial type (Valid, Neutral, and Invalid) $\times$ Target Side (left, right) repeated-measures ANOVA.

Reaction times. Due to the high number of omissions of targets in the left side of space, RTs were analyzed through two different procedures. First (analysis A), only RTs provided by patients were considered in the analysis. Second (analysis B), to allow comparison with other recent RTs investigations in neglect patients (Regachary et al., 2011), omitted RTs were replaced with the maximum time allowed for response (2000 ms). In both analyses $\mathrm{A}$ and $\mathrm{B}$, individual mean RTs were entered in a mixed Group $(\mathrm{C}, \mathrm{N}-$, and $\mathrm{N}+$ ) and Trial type (Valid, Neutral, and Invalid) $\times$ Target Side (left, right) repeated-measures ANOVA.

\section{ERP data}

\section{Lateralized cue-related components}

The three lateralized, long lasting, and large-amplitude preparatory ERP components (EDAN, ADAN, and LDAP) that were elicited by central spatial cues were averaged within six conventional ROIs (Kelly et al., 2009): left frontal (FL; F7, FC5), right frontal (FR; F8, FC6), left posterior (PL; $\mathrm{P} 7, \mathrm{CP} 5)$, right posterior (PR; P8, CP6), left occipital (LO; PO7, O1), and right occipital (RO; PO8, $\mathrm{O}_{2}$ ). In a first series of analyses, each component was analyzed by entering individual data in a $\operatorname{Group}(\mathrm{C}, \mathrm{N}-, \mathrm{N}+) \times$ Cue Direction (left, right) $\times$ Hemisphere (left, right) repeated-measures ANOVA. The amplitude of these components were measured as mean activity with respect to a $200 \mathrm{~ms}$ prestimulus baseline in the following conventional time windows: EDAN (240-420 ms post-cue, PL and PR; Seiss et al., 2009; Kelly et al., 2010), ADAN (450-850 ms post-cue, FL and FR; Eimer et al., 2002; Seiss et al., 2009), and LDAP (500-1000 ms postcue, PL and PR; Eimer et al., 2002; Seiss et al., 2009) in all groups.

Harter et al. (1989) and Nobre et al. (2000) pointed out that the ADAN and LDAP components can persist for the entire duration of the cue period up to target appearance. Based on this suggestion, in a second series of analyses we explored the development and maintenance of the ADAN and LDAP during the entire cue period adopted in the present study. To this aim, we reanalyzed through the same series of repeated-measures ANOVAs, the ADAN and LDAP during the first half and the second half of the cue period that ranged from the onset of each component to the end of the cue period, i.e., $1800 \mathrm{~ms}$, that was shared by the different cue durations that preceded target presentation. The ADAN was reanalyzed within the 450-1125 and 1125-1800 ms time windows. The LDAP was reanalyzed within the 500-1150 and 1150-1800 ms time windows.

\section{Target-related components \\ $P 3 a$ and $P 3 b$}

The amplitude of $\mathrm{P} 3 \mathrm{a}$ and $\mathrm{P} 3 \mathrm{~b}$ components was measured as the mean activity change with respect to a $200 \mathrm{~ms}$ prestimulus baseline in the following time windows: P3a, $220-380 \mathrm{~ms}$; P3b, 300-600 ms. Both components were analyzed at the following pools of derivations: (1) P3a: AFz, Fz, Fcz, F1, F2 (see Fig. 6); and (2) P3b: P1, P3, PO1, PO3, Pz, POz, $\mathrm{Oz}, \mathrm{P} 2, \mathrm{P} 4, \mathrm{PO} 2, \mathrm{PO} 4$ (see Fig. 7). The selection of time windows and derivations used for the analysis of these large amplitude components were based on the results of previous studies (Polich, 2007; Saevarsson et al., 2012) and on visual inspection of scalp topographies. Individual data were entered in a Group $(\mathrm{C}, \mathrm{N}-$, and $\mathrm{N}+) \times$ Trial type (Valid, Neutral, and Invalid) $\times$ Target side (left, right) repeated-measures ANOVA. Latency peaks of the P3a and P3b components were estimated through an automatic peak-detection algorithm (Vision Analyzer 2.1.2) within the same time windows and electrode derivations used in amplitude analyses. All peaks identified by the software were further verified through visual inspection. Individual latencies were entered in a Group (C, N-, and $\mathrm{N}+) \times$ Trial type (Valid, Neutral, and Invalid) $\times$ Target side (left, right) repeated-measures ANOVA.

\section{P1 and N1}

Individual amplitudes and latency peaks of these small amplitude transitory ERP components were estimated through an automatic peak-detection algorithm (Vision Analyzer 2.1.2) within specified time windows (P1: 90-200 $\mathrm{ms}$; N1: 150-250 ms). Peak detection was performed at electrode derivations, (PO7/8, CP3/4), where these components showed maximal amplitude in the grand average of each experimental group (Di Russo et al., 2008). Time windows and derivation are consistent with those used in the large majority of previous studies (Gomez Gonzalez et al., 1994; Lasaponara et al., 2011; Slagter et al., 2016). All peaks identified by the software were further verified through visual inspection. Individual latency and amplitude $\mathrm{P} 1$ peaks were successively entered in a Group $(\mathrm{C}, \mathrm{N}-$, $\mathrm{N}+$ ) $\times$ Target side (left, right $) \times$ Hemisphere (Ipsilateral, Contralateral) repeated-measures ANOVA, whereas individual latency peaks of the N1 recorded over the hemisphere contralateral to target side were entered in a Group $(\mathrm{C}, \mathrm{N}-, \mathrm{N}+) \times$ Target side (left, right) repeated-measures ANOVA.

In a series of additional analyses, we investigated whether valid attentional cuing produced an increase in the amplitude of the $\mathrm{P} 1$ and $\mathrm{N} 1$ with respect to invalid cuing, i.e., sensory gain (Mangun and Hillyard, 1991). To this aim we initially calculated individual differential P1 and N1 waveforms between Valid and Invalid targets within each patient and participant. This served to partially control for the potential confounds that would have been produced if the contrast between Valid and Invalid targets would have been initially run between groups of patients with brain lesions differing in site and size. In a first step, through a series of one-sample $t$ test, we checked whether the mean differential amplitude of the P1 and N1 components was significantly different from zero in each experimental group. In a second step, differential P1 waveforms were entered in Group $(\mathrm{C}, \mathrm{N}-, \mathrm{N}+) \times$ Target side (left, right $) \times$ Hemisphere (Ipsilateral, Contralateral) repeated-measures ANOVA, and differential $\mathrm{N} 1$ waveform in a Group $(\mathrm{C}, \mathrm{N}-, \mathrm{N}+) \times$ Target side (left, right) repeated-measures ANOVA.

The influence of attentional cuing on peak-latencies was tested by entering individual $\mathrm{P} 1$ data in a Group $(\mathrm{C}, \mathrm{N}-, \mathrm{N}+) \times$ Trial type (Valid, Invalid) $\times$ Target side (left, right) $\times$ Hemisphere (Ipsilateral, Contralateral) repeated-measures ANOVA, and $\mathrm{N} 1$ data in a Group (C, N-, 


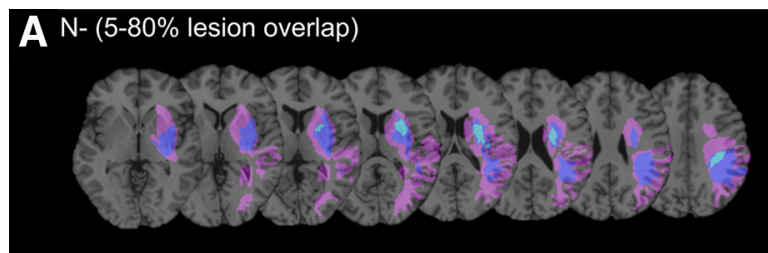

$\mathrm{N}+(5-80 \%$ lesion overlap)

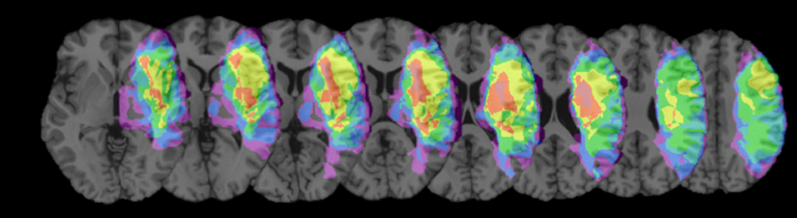

$(\mathrm{N}+)$ - (N-) subtraction

$5-80 \%$ lesion overlap

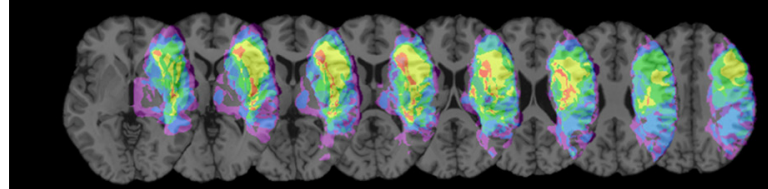

$50-80 \%$ lesion overlap

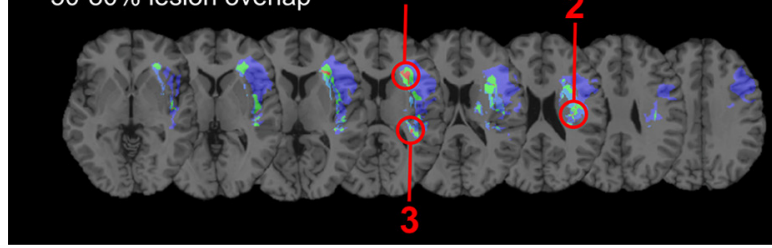

B 1: 30268 - Frontal Operculum

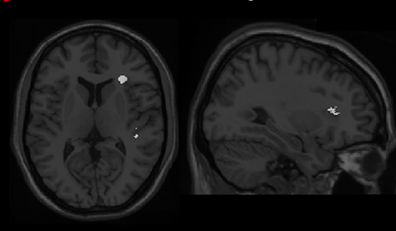

$2: 34$-19 22 - Anterior segment/Arcuate fasciculus (AF)


3 : Planum temporale

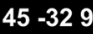

$44-284$

$43-22-1$

$42-2410$

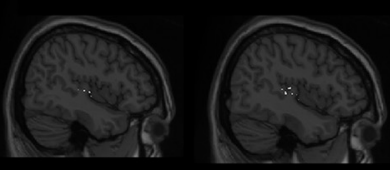

$38-3511$ Posterior segment (AF)

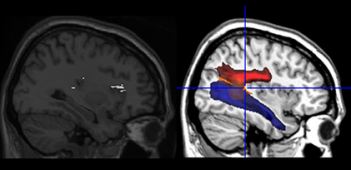

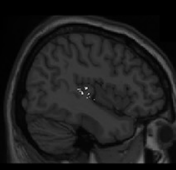

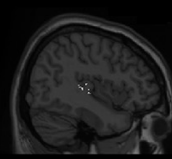

$35-3612$

Posterior segment (AF)

Figure 1. A, Overlay of lesions in $\mathrm{RBD}$ patients without left spatial neglect $(\mathrm{N}-$ ) with left spatial neglect $(\mathrm{N}+$ ) and lesion probability maps resulting from the $\mathrm{N}+$ minus $\mathrm{N}-$ subtraction (range: $5-80 \%$ or $50-80 \%$ ). Areas of maximal lesion overlap resulting from the subtraction (differential overlap $=78 \%$ ) are highlighted by numbered red circles. $\boldsymbol{B}$, Anatomical details of areas of maximal lesion overlap numbered in $\boldsymbol{A}$. (1) Frontal operculum (MNI coordinates: 30, 26, 8); (2) anterior segment (purple) of the arcuate fasciculus (red; MNI coordinates: 34 , - 19, 22); and (3) posterior sector of the superior temporal gyrus-planum temporale (MNI coordinates: $45,-32,9 ; 44,-28,4 ; 43,-22,-1 ; 42,-24,10$ ); posterior segment (orange) of the arcuate fasciculus (red) and inferior longitudinal fasciculus (blue; MNI coordinates: $38,-35,11 ; 35,-36,12$ ).

$\mathrm{N}+$ ) $\times$ Trial type (Valid, Invalid) $\times$ Target side (left, right) repeatedmeasures ANOVA for the N1.

\section{Results}

\section{Clinical results}

A series of between-group comparisons, showed that compared with $\mathrm{N}-, \mathrm{N}+$ patients had significant rightward spatial biases in all neglect tasks (Table 1 ). $\mathrm{N}+$ had a higher rightward bias during line bisection $\left(t_{(23)}=-4.1, p=0.0003\right.$, unpaired $t$ test $)$ and showed a higher number of left side omissions in the Sentence reading task $\left(t_{(23)}=3.3, p=0.002\right.$, unpaired $t$ test $)$. In the Letter cancellation $\left(F_{(1,23)}=16.5, p=0.0004, \eta_{p}^{2}=0.41\right)$, Line cancellation $\left(F_{(1,23)}=\right.$ $\left.10.4, p=0.003, \eta_{p}^{2}=0.31\right)$, Star Cancellation $\left(F_{(1,23)}=22.8, p=\right.$ $\left.0.0000, \eta_{p}^{2}=0.49\right)$, and in the Wundt-Jastrow Area illusion task $\left(F_{(1,23)}=18.3, p=0.0002, \eta_{p}^{2}=0.44\right)$, the performance of $\mathrm{N}+$ differed from that of $\mathrm{N}-$ more for stimuli positioned in the left side of space than for stimuli positioned in the right side of space, as indexed by significant Group $\times$ Side interactions.

\section{Anatomical results}

$\mathrm{N}+$ patients had larger lesion than $\mathrm{N}-$ ones $\left(F_{(1,23)}=12.7, p=\right.$ $\left.0.002, \eta_{p}^{2}=0.42\right)$. The lesion probability maps resulting from the subtractions between $\mathrm{N}+$ and $\mathrm{N}-$ showed three areas of $78 \%$ lesion overlap in $\mathrm{N}+$ and no overlap, i.e., $0 \%$, in $\mathrm{N}-$ patients (Fischer exact test, $p=0.0003$ ). A first anterior peak of lesion overlap was located in the frontal operculum (MNI coordinates: 30, 26, 8; Fig. 1, Peak 1). A second peak was located in the anterior segment of the arcuate fasciculus (MNI coordinates: 34, - 19, 22;
Fig. 1, Peak 2). Finally a third peak was found in cortical and subcortical structures around the temporal parietal junction (TPJ; Fig. 1, Peak 3; Heschl gyrus: 43, $-22,-1$, and 42, -24, 10; posterior sector of the superior temporal gyrus: $44,-28,4$; planum temporale: $45,-32,9$; posterior segment of the arcuate fasciculus also close to the inferior longitudinal fasciculus: 38, $-35,11$, and $35,-36,12$ ).

The $\mathrm{N}+$ versus $\mathrm{N}-$ comparison run on individual probabilities of disconnection defined by the Tractotron software showed higher probability of disconnection in the $\mathrm{N}+$ group in each of the tracts highlighted in the study of lesion overlap (anterior segment of the arcuate fasciculus: $\mathrm{N}+=89 \%, \mathrm{~N}-=$ $46 \%, F_{(1,23)}=4.93, p=0.04, \eta_{p}^{2}=0.22$; posterior segment of the arcuate fasciculus: $\mathrm{N}+=83 \%, \mathrm{~N}-=44 \%, F_{(1,23)}=5.41$, $p=0.03, \eta_{p}^{2}=0.24$; inferior longitudinal fasciculus: $\mathrm{N}+=$ $\left.83 \%, \mathrm{~N}-=36 \%, F_{(1,23)}=6.6, p=0.01, \eta_{p}^{2}=0.28\right)$. When the same comparisons were run taking into account lesion volume as covariate, no significant difference was found between $\mathrm{N}+$ and $\mathrm{N}-$. This result illustrates that lesion volume increases the probability of white-matter disconnection and of the presence of spatial neglect.

\section{Behavioral results}

\section{Omissions}

$\mathrm{N}+$ made more omissions (37.3\%; Group effect: $F_{(2,37)}=22.8$; $\left.p=0.0000, \eta_{p}^{2}=0.55\right)$ than $\mathrm{N}-(15.5 \%, p=0.0006)$ and $\mathrm{C}$ $(4.3 \% p=0.0000)$. The ANOVA highlighted a significant 
Group $\times$ Trial type $\times$ Target side interaction $\left(F_{(4,74)}=2.6 ; p=\right.$ $\left.0.03, \eta_{p}^{2}=0.13\right)$. This triple interaction was further analyzed through two ANOVAs comparing $\mathrm{C}$ with $\mathrm{N}+$ and $\mathrm{N}-$ groups separately. The Group $(\mathrm{C}, \mathrm{N}-) \times$ Trial type (Valid, Neutral, and Invalid) $\times$ Side of target (left, right) ANOVA showed that $\mathrm{N}-$ made more omissions than $\mathrm{C}$ (Group effect: $F_{(1,26)}=23 p=$ $\left.0.0000, \eta_{p}^{2}=0.46\right)$. A significant Group $\times$ Target side interaction showed that compared with $\mathrm{C}$, in the $\mathrm{N}-$ group omissions were more frequent for targets in the left side of space $\left(F_{(1,26)}=15.1\right.$, $p=0.0006, \eta_{p}^{2}=0.36$; left side: $\mathrm{N}-=20 \%, \mathrm{C}=3 \%$; right side: $\mathrm{N}-=10 \%, \mathrm{C}=4 \%)$ and that this happened independently of Trial type (Group $\times$ Trial type $\times$ Target side interaction: $F_{(2,52)}<$ $1, P=$ n.s). The Group (C, N+) $\times$ Trial type (Valid, Neutral, and Invalid) $\times$ Side of target (left, right) ANOVA showed that compared with $\mathrm{C}, \mathrm{N}+$ made more omissions $\left(F_{(1,25)}=36.5, p=\right.$ $\left.0.0000, \eta_{p}^{2}=0.59\right)$ and that this omissions were more frequent in the left side of space $\left(F_{(1,25)}=34.2, p=0.0000, \eta_{p}^{2}=0.57\right.$; left side: $\mathrm{N}+=51 \%, \mathrm{C}=3 \%$; right side: $\mathrm{N}+=23 \%, \mathrm{C}=4 \%$ ). Most important, a significant Group $\times$ Trial type $\times$ Target side interaction $\left(F_{(2,50)}=3.4, p=0.03, \eta_{p}^{2}=0.12\right)$ showed that compared with $\mathrm{C}$, in $\mathrm{N}+$ omissions in the left side of space increased as a function of trial type: they were less frequent with valid targets $(38 \%)$, intermediate with neutral targets $(52 \%)$, and reached the highest level with invalid targets $(62 \%)$. This result highlights the reorienting deficit suffered by $\mathrm{N}+$ patients (Posner et al., 1984). Finally, we compared the performance of $\mathrm{N}+$ and $\mathrm{N}-$ patients through a Group $(\mathrm{N}+, \mathrm{N}-) \times$ Trial type (Valid, Neutral, and Invalid) $\times$ Side of target (left, right) ANOVA. $N+$ made more omissions than $\mathrm{N}-$ patients $\left(F_{(1,23)}=9.3, p=0.005, \eta_{p}^{2}=0.28\right)$. A Group $\times$ Target side interaction $\left(F_{(2,46)}=7.4, p=0.01, \eta_{p}^{2}=\right.$ 0.24 ) showed that compared with $\mathrm{N}-, \mathrm{N}+$ made more omissions in the left side of space though not in the right side (left side: $\mathrm{N}+=$ $51 \%, \mathrm{~N}-=20 \%$, Bonferroni post hoc test $p=0.0003$; right side: $\mathrm{N}+=23 \%, \mathrm{~N}-=10 \%, p=0.53)$. We also found a significant triple Group $\times$ Trial type $\times$ Target side interaction $\left(F_{(2,46)}=3.8\right.$, $\left.p=0.02, \eta_{p}^{2}=0.14\right)$. Separate Group $\times$ Trial type ANOVAs run for the left and right side of space showed that compared with $\mathrm{N}-$, in $\mathrm{N}+$ omissions in the left side of space grew up as function of Trial type (Group $\times$ Trial type interaction: $F=4.1, p=0.02$; $\mathrm{N}+$ : Valid $=38 \%$, Neutral $=52 \%$, Invalid $62 \% ; \mathrm{N}-$ : Valid $=$ $16 \%$, Neutral $=19 \%$, Invalid 24\%). A similar interaction was not present when targets were presented in the right side of space (Group $\times$ Trial type interaction: $F<1$; Fig. 2).

\section{RTs}

Analysis A

A significant Trial type effect showed the presence of attentional benefits, i.e., RTs advantage for Valid compared with Neutral targets, and costs, i.e., RTs disadvantage of Invalid compared with Neutral targets $\left(F_{(2,74)}=25.9, p=0.0000, \eta_{p}^{2}=0.41 ;\right.$ Valid $=510$ $\mathrm{ms}$, Neutral $=547 \mathrm{~ms}$, Invalid $=568 \mathrm{~ms}$ : Bonferroni post hoc comparisons $p=0.01$ and $p=0.03$ for costs and benefits, respectively). A Group $\times$ Target side interaction $\left(F_{(2,37)}=4.7 ; p=0.01\right.$, $\left.\eta_{p}^{2}=0.20\right)$ showed that compared with $\mathrm{C}, \mathrm{N}+$ had slower responses to targets presented in the left side of space, though not for those in the right side (left: $\mathrm{C}=511.2 \mathrm{vs} \mathrm{N}+=568.5, p=$ 0.03 ; right: $\mathrm{C}=507.8$ vs $\mathrm{N}+=569, p=0.11)$. RTs of $\mathrm{N}-$ were comparable with those of $\mathrm{C}$ in both sides of space. No significant difference was found between $\mathrm{N}+$ and $\mathrm{N}-$.

Analysis B

$\mathrm{N}+$ had slower RTs (1100 ms) compared with both C (500 ms $p=0.0001)$ and $\mathrm{N}-$ patients $(800 \mathrm{~ms} p=0.003$; Group effect:
$\left.F_{(2,37)}=19.3 ; p=0.0000, \eta_{p}^{2}=0.51\right)$. A significant Trial type effect showed the presence of attentional benefits and costs $\left(F_{(2,74)}=34, p=0.0000, \eta_{p}^{2}=0.47\right.$; Valid $=701 \mathrm{~ms}$, Neutral $=$ $783 \mathrm{~ms}$, Invalid $=865 \mathrm{~ms}$ : Bonferroni post hoc comparisons $p=$ 0.01 and $p=0.003$ for costs and benefits, respectively). A Group $\times$ Target side interaction $\left(F_{(2,37)}=14.2 ; p=0.0000, \eta_{p}^{2}=\right.$ 0.43 ) highlighted that compared with $\mathrm{C}, \mathrm{N}+$ had slower responses to target appearing both in the left and in the right side of space (left: $\mathrm{C}=511.2$ vs $\mathrm{N}+=1323.5, p=0.0000$; right: $\mathrm{C}=$ 507.8 vs $\mathrm{N}+=899.1, p=0.0000)$. Conversely, compared with $\mathrm{N}-, \mathrm{N}+$ had slower RTs for targets in the left side of space, whereas the same difference did not reach significance for targets in the right side of space (left: $\mathrm{N}-=886.1$ vs $\mathrm{N}+=1323.5, p=$ 0.0000 ; right: $\mathrm{N}-=689$ vs $\mathrm{N}+=899, p=0.055)$. Compared with $\mathrm{C}, \mathrm{N}-$ had slower responses for targets in the left side of space (left: $\mathrm{C}=511$ vs $\mathrm{N}-=886, p=0.001$; right: $\mathrm{C}=507 \mathrm{vs}$ $\mathrm{N}-=689, p=0.12$; Fig. 2).

\section{Electrophysiological results \\ Cue-related ERPs}

Grand averages of cue-related EDAN, ADAN, and LDAP components elicited by cues pointing to the left or the right side of space in the six ROIs (FL, FR, PL, PR, OL, and OR) are illustrated in Figures 3,4 , and 5 for $\mathrm{C}, \mathrm{N}-$, and $\mathrm{N}+$ participants, respectively.

\section{EDAN}

The Group $\times$ Cue direction $\times$ Hemisphere interaction was significant $\left(F_{(2,37)}=3.4, p=0.04, \eta_{p}^{2}=0.14\right)$. Bonferroni post hoc comparison showed that in $\mathrm{C}$ the EDAN was present both over the left and over the right hemisphere (left hemisphere: cue in the contralateral direction $=-0.96 \mu \mathrm{V}$, cue in the ipsilateral direction $=-0.60 \mu \mathrm{V}, p=0.03$; right hemisphere: cue contralateral $=$ $-0.54 \mu \mathrm{V}$, cue ipsilateral $=-0.12 \mu \mathrm{V}, p=0.03)$. In $\mathrm{N}-$ the EDAN was present over the left hemisphere (cue contralateral $=$ $13 \mu \mathrm{V}$, cue ipsilateral $=64 \mu \mathrm{V} ; p=0.02$ ), whereas over the right hemisphere there was a nonsignificant reversal of the component, with relative higher voltage for the cue in the contralateral direction (cue contralateral $=75 \mu \mathrm{V}$, cue ipsilateral $=35 \mu \mathrm{V}$ ). No EDAN was present in $\mathrm{N}+$.

These results suggest that $\mathrm{N}+$ suffer a general and spaceindependent deficit in the early phases of the attentional shift and/or the spatial selection of cue-features that guide lateral shifts of attention. In contrast, $\mathrm{N}-$ patients display this deficit only for cues pointing in the contralesional direction, i.e., leftward.

\section{ADAN}

The Group $\times$ Cue direction $\times$ Hemisphere ANOVA highlighted the bilateral presence of the ADAN in all Groups (Cue direction $\times$ Hemisphere interaction: $F_{(1,37)}=37, p=0.0000, \eta_{p}^{2}=$ $0.50)$. There was also a significant main Group effect $\left(F_{(2,37)}=\right.$ 3.7, $\left.p=0.03, \eta_{p}^{2}=0.16\right)$. Bonferroni post hoc comparisons showed that this was due to general higher negativity in $\mathrm{N}+$ compared with $\mathrm{C}(-0.67 \mu \mathrm{V}$ vs $0.27 \mu \mathrm{V}, p=0.02)$.

\section{First half of the cue period}

The Group $\times$ Cue direction $\times$ Hemisphere ANOVA highlighted bilateral ADAN in all Groups (Cue direction $\times$ Hemisphere interaction: $\left.F_{(1,37)}=9, p=0.004, \eta_{p}^{2}=0.19\right)$.

Second half of the cue period

The Group $\times$ Cue direction $\times$ Hemisphere interaction was significant $\left(F_{(2,37)}=4.8, p=0.01, \eta_{p}^{2}=0.20\right)$ and highlighted a bilateral ADAN in C left hemisphere: cue contralateral $=0.27 \mu \mathrm{V}$, 
A

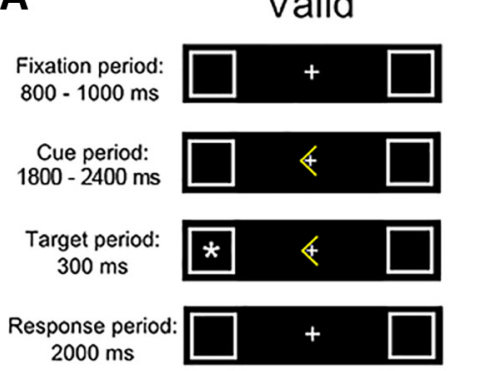

Invalid

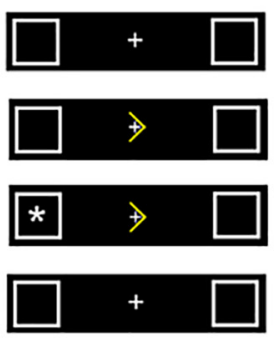

Neutral

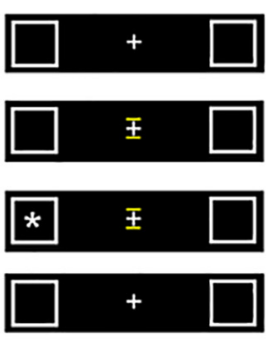

Directional Catch
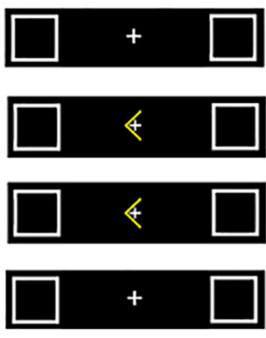

Neutral Catch

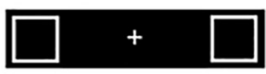

$\square \quad$ 王
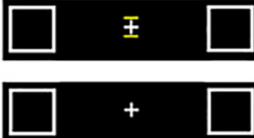

\section{B}
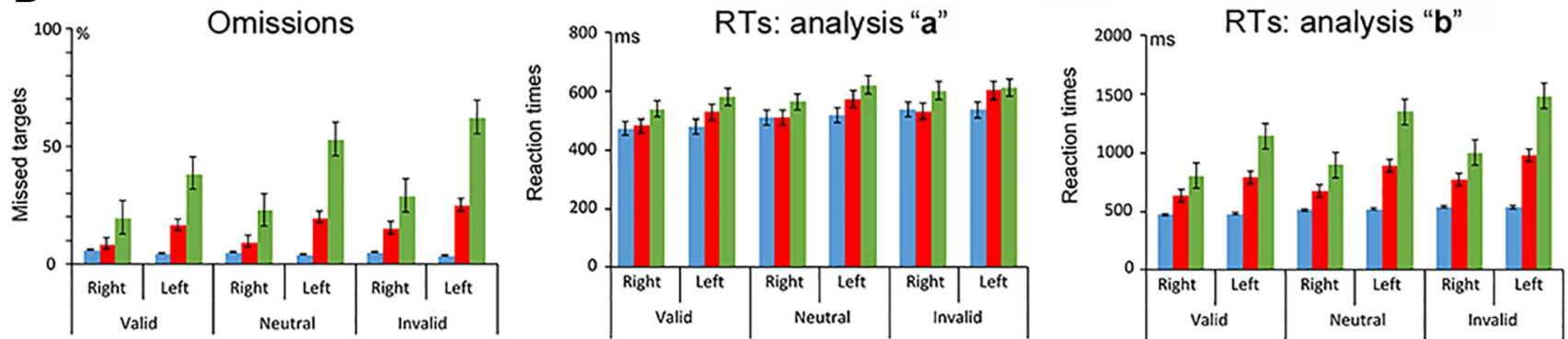

$\mathrm{HC} \square \mathrm{N}-\square \mathrm{N}+$

Figure 2. A, Time course of events during directional (Valid, Invalid), nondirectional (Neutral), and Catch experimental trials. Duration of events is reported in milliseconds. B, Behavioral performance of healthy controls ( $\mathrm{HC}$; blue), RBD patients with left spatial neglect ( $\mathrm{N}+$; green) and patients without neglect ( $\mathrm{N}-$; red) in the Posner task: average percentages of omissions with Valid, Neutral, and Invalid targets. Uncorrected average RTs to Valid, Neutral, and Invalid targets (see Materials and Methods, analysis " $\mathrm{a}^{\prime \prime}$ ); corrected average RTs to Valid, Neutral, and Invalid targets (omissions are replaced with maximal time allowed for response $=2000 \mathrm{~ms}$; see Materials and Methods, analysis "b"). Error bars indicate SE.

cue ipsilateral $=0.53 \mu \mathrm{V}, p=0.05$; right hemisphere: cue contralateral $=-0.26 \mu \mathrm{V}$, cue ipsilateral $-0.40 \mu \mathrm{V}, p=0.002$ ), though no significant ADAN in $\mathrm{N}$ - (left hemisphere: cue contralateral $=0.30 \mu \mathrm{V}$, cue ipsilateral $=0.59 \mu \mathrm{V}, p=0.54$; right hemisphere: cue contralateral $=0.16 \mu \mathrm{V}$, cue ipsilateral $0.47 \mu \mathrm{V}$, $p=0.41)$ and $\mathrm{N}+$ (left hemisphere: cue contralateral $=-0.06$ $\mu \mathrm{V}$, cue ipsilateral $=-0.46 \mu \mathrm{V}, p=0.42$; right hemisphere: cue contralateral $=0.62 \mu \mathrm{V}$, cue ipsilateral $0.37 \mu \mathrm{V}, p=0.62$ ).

These findings highlight sparing of supramodal frontal mechanisms of attentional engagement in all groups of patients.

\section{LDAP}

The Group $\times$ Cue direction $\times$ Hemisphere interaction was significant $\left(F_{(2,37)}=3.4, p=0.04, \eta_{p}^{2}=0.13\right)$ Bonferroni post hoc comparisons showed that in $\mathrm{C}$ the LDAP was present in both hemispheres (left hemisphere: cue contralateral $=0.44 \mu \mathrm{V}$, cue ipsilateral $=-0.18 \mu \mathrm{V}, p=0.006$; right hemisphere: cue contralateral $=0.18 \mu \mathrm{V}$, cue ipsilateral $-0.33 \mu \mathrm{V}, p=0.02$ ), whereas in $\mathrm{N}-$ it was only found over the right hemisphere (left hemisphere: cue contralateral $=0.34 \mu \mathrm{V}$, cue ipsilateral $=0.11 \mu \mathrm{V}$, $p=0.43$; right hemisphere: cue contralateral $=0.14 \mu \mathrm{V}$, cue ipsilateral $=-0.43 \mu \mathrm{V}, p=0.01$ ).

First half of the cue period

The Group $\times$ Cue direction $\times$ Hemisphere interaction was significant $\left(F_{(2,37)}=3.5, p=0.04, \eta_{p}^{2}=0.14\right)$. Bonferroni post hoc comparisons showed that in $\mathrm{C}$ the LDAP was present in both hemispheres (left hemisphere: cue contralateral $=0.11 \mu \mathrm{V}$, cue ipsilateral $=-0.30 \mu \mathrm{V}, p=0.0000$; right hemisphere: cue contralateral $=0.09 \mu \mathrm{V}$, cue ipsilateral $-0.47 \mu \mathrm{V}, p=0.0001$ ), whereas in $\mathrm{N}-$ it was only found over the right hemisphere (left hemisphere: cue contralateral $=0.35 \mu \mathrm{V}$, cue ipsilateral $=0.008$ $\mu \mathrm{V}, p=0.26$; right hemisphere: cue contralateral $=0.61 \mu \mathrm{V}$, cue ipsilateral $=-0.01 \mu \mathrm{V}, p=0.04)$. No LDAP was found in $\mathrm{N}+$ (right hemisphere $p=0.57$; left hemisphere $p=0.17$ ).

Second half of the cue period

The Group $\times$ Cue direction $\times$ Hemisphere interaction was significant $\left(F_{(2,37)}=4.6, p=0.01, \eta_{p}^{2}=0.19\right)$ and highlighted a bilateral LDAP in the $\mathrm{C}$ (left hemisphere: cue contralateral $=-0.18 \mu \mathrm{V}$, cue ipsilateral $=-0.71 \mu \mathrm{V}, p=0.0003$; right hemisphere: cue contralateral $=-0.70 \mu \mathrm{V}$, cue ipsilateral $-0.01 \mu \mathrm{V}, p=0.0003)$ and in the $\mathrm{N}-$ group (left hemisphere: cue contralateral $=0.41 \mu \mathrm{V}$, cue ipsilateral $=-0.34 \mu \mathrm{V}, p=0.04$; right hemisphere: cue contralateral $=$ $0.50 \mu \mathrm{V}$, cue ipsilateral $-0.26 \mu \mathrm{V}, p=0.04)$. No LDAP was present in $\mathrm{N}+$ (left hemisphere: cue contralateral $=0.34 \mu \mathrm{V}$, cue ipsilateral $=-0.28 \mu \mathrm{V}, p=0.76$; right hemisphere: cue contralateral $=$ $0.49 \mu \mathrm{V}$, cue ipsilateral $0.26 \mu \mathrm{V}, p=0.84$ ).

These results suggest preserved setting-up of facilitatory effects in posterior visual areas of both hemispheres in $\mathrm{HC}$ and $\mathrm{N}-$ patients, though delayed over the left hemisphere in the latter group, and bilateral loss of these facilitatory effects in $\mathrm{N}+$.

\section{Target-related ERPs}

Grand average of target-related ERPs in the C, N-, and $\mathrm{N}+$ groups are illustrated in Figures 6, 7, and 8 respectively.

\section{P300}

P3a

Latency. No significant main effect or interaction was found in the analysis of latency peaks (all $F<2$ and all $p>0.10$ ).

Amplitude. The triple Group $\times$ Trial type $\times$ Target side interaction was significant $\left(F_{(4,74)}=6.6, p=0.0001, \eta_{p}^{2}=0.26\right)$. Post hoc comparisons pointed out that compared with $\mathrm{C}$ and $\mathrm{N}-, \mathrm{N}+$ had reduced $\mathrm{P} 3 \mathrm{a}$ in response to left Invalid targets $(\mathrm{N}+=-1.1$ $\mu \mathrm{V}, \mathrm{C}=1.6 \mu \mathrm{V}, p=0.003 ; \mathrm{N}+=-1.1 \mu \mathrm{V}, \mathrm{N}-=1.1 \mu \mathrm{V}, p=$ 


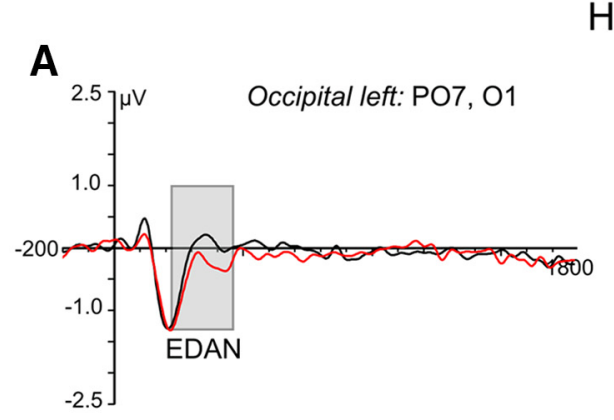

\section{Healthy controls $(\mathrm{HC})$}
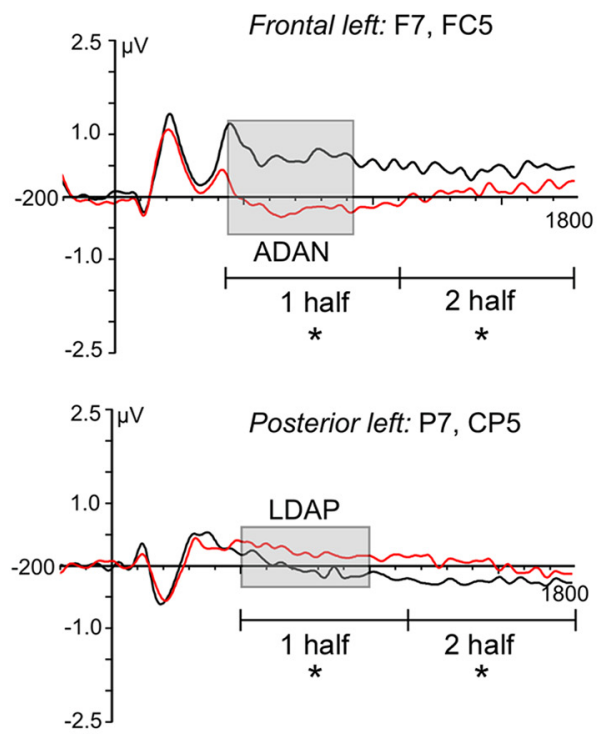


B Cue left - Cue right
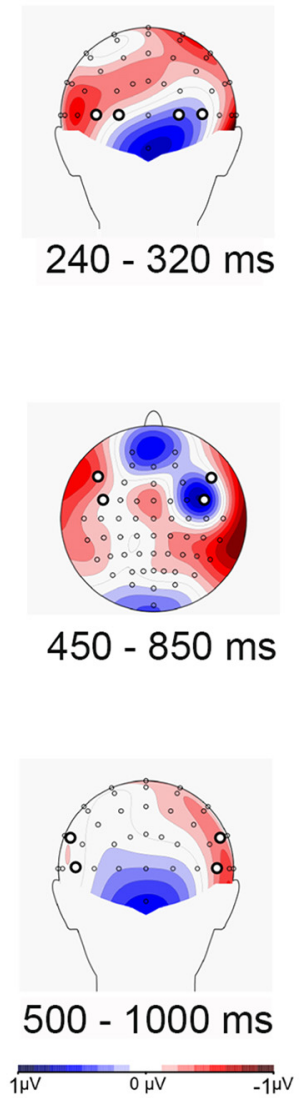

\section{Cue left}

\section{Cue right}

Figure 3. A, Cue-related ERP components recorded in healthy controls (HC) during directional trials with arrow-cues pointing to the left (black line) or the right (red line). ERPs recorded over the left and the right hemisphere, are reported separately for the anterior, occipital, and posterior pools of derivations (see Materials and Methods). Conventional time windows used for the analysis of lateralized responses associated to attentional orienting (i.e., EDAN, ADAN and LDAP) are highlighted by gray squares (full squares = significant difference between ipsilateral and contralateral waveforms; empty squares = nonsignificant difference). Horizontal bars below the ADAN and LDAP highlight the first and second half of the cue period (see Materials and Methods). Asterisks indicate a significant difference between ipsilateral and contralateral waveforms in the corresponding half of the cue period. $\boldsymbol{B}$, Scalp topographic maps representing the amplitude of differential "Cue-right - Cue-left" waveforms.

$0.01)$ and increased $\mathrm{P} 3 \mathrm{a}$ for right Invalid target $(\mathrm{N}+=3.1 \mu \mathrm{V}$, $\mathrm{C}=1.2 \mu \mathrm{V}, p=0.04 ; \mathrm{N}+=3.1 \mu \mathrm{V}, \mathrm{N}-=0.93 \mu \mathrm{V}, p=0.02)$. No difference was found between $\mathrm{C}$ and the $\mathrm{N}-($ all $p>0.58)$. The Target side main effect and the Group $\times$ Target side interaction were also significant (both $F>6.2$ and both $p<0.004$ ): both of these effects are explained by the increased amplitude of the $\mathrm{P} 3 \mathrm{a}$ in response to right Invalid targets in $\mathrm{N}+$ highlighted by the triple Group $\times$ Trial type $\times$ Target side interaction (Fig. 6). All other main effects and interactions were not significant (all $F<2$ and all $p>0.13$ ). In line with previous studies run in elderly adults with the Posner task (Curran et al., 2001), in the sample of HC tested in our study the amplitude of the P3a was not enhanced by invalid cuing (though see a significant validity effects for the P3b in the related result section). Dissociations between P3a amplitude and validity effects in the Posner task were also described in young children (Flores et al., 2010). All together these results show that changes in the amplitude or latency of the $\mathrm{P} 3$ are not necessarily linked to changes in the detection or speed of detection of invalid or other types of attentional targets.
These data suggest exaggerated novelty reaction to targets in the right side of space and reduced novelty reaction for those in the left side in $\mathrm{N}+$ patients.

\section{P3b}

Latency. The analysis of latency peaks revealed a significant Group $\times$ Trial type $\times$ Target side interaction $\left(F_{(4,74)}=3.2, p=\right.$ $\left.0.01, \eta_{p}^{2}=0.18\right)$. This interaction pointed out that, independently of target side, in $\mathrm{HC}$ the $\mathrm{P} 3 \mathrm{~b}$ response to Invalid targets was delayed compared with both Valid and Neutral targets (Invalid = left $500 \mathrm{~ms}$, right $496 \mathrm{~ms}$; Neutral = left $427 \mathrm{~ms}$, right $425 \mathrm{~ms}$; Valid = left $424 \mathrm{~ms}$, right $426 \mathrm{~ms}$; all $p<0.0001$ ). In contrast, in $\mathrm{N}-$ no significant difference in latency peak was found as a function of target type or target side. Finally, in $\mathrm{N}+$ the latency peak of the P3b was anticipated for left Valid targets (384 ms) compared with both left Neutral (537 ms) and left Invalid (494 ms) targets (all $p<0.0001$ ): this effect was superimposed on a general drop in the amplitude of the $\mathrm{P} 3 \mathrm{~b}$ in response to target in the left side of space (see next section). In $\mathrm{N}+$ no difference in latency peak was 
RBD patients without neglect (N-)
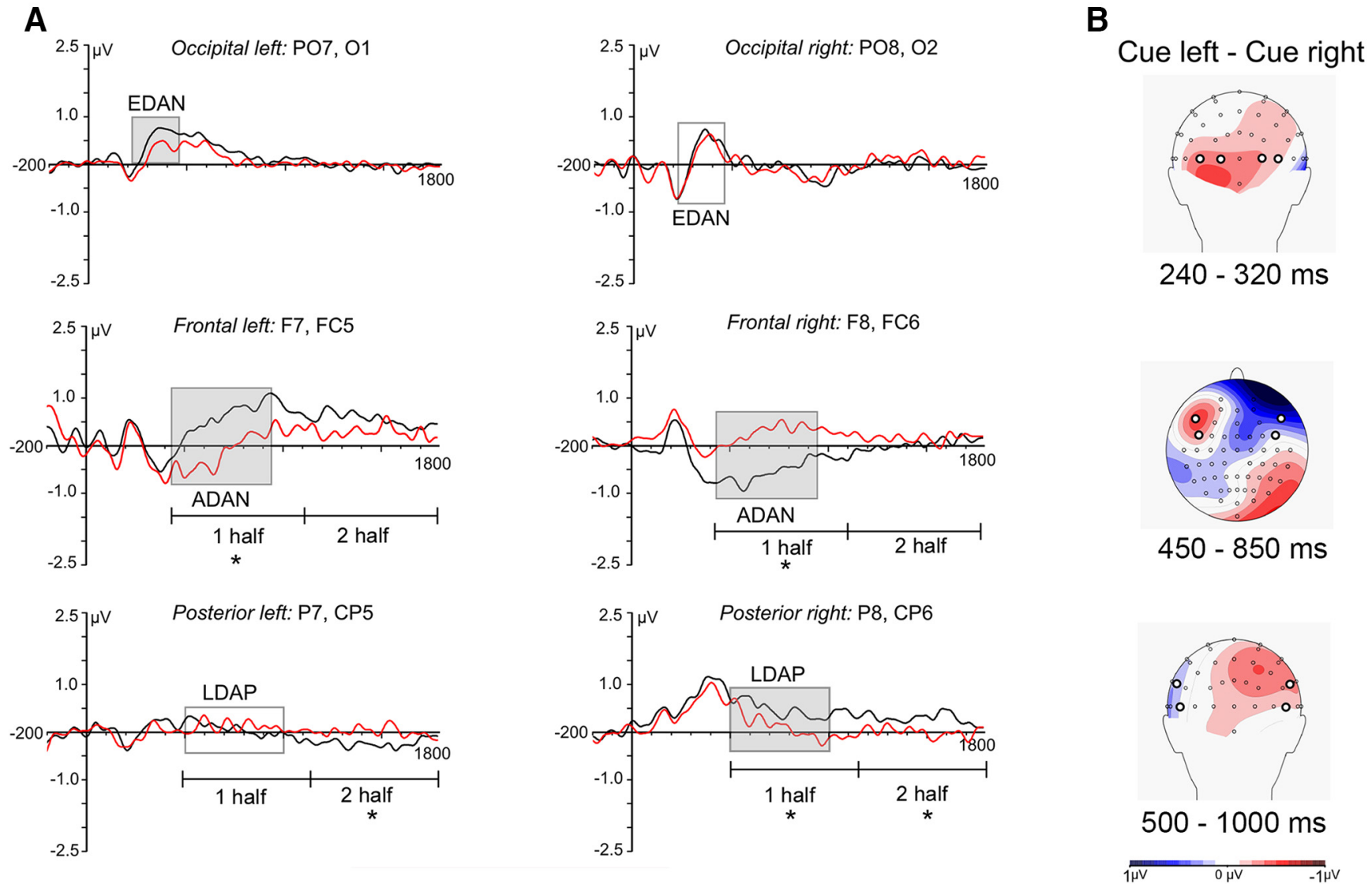

\section{Cue left} Cue right

Figure 4. A,Cue-related ERP components recorded in RBD patients without left spatial neglect ( $\mathrm{N}-$ ) during directional trials with arrow-cues pointing to the left (black line) or the right (red line). $B$, Scalp topographic maps representing the amplitude of differential "Cue-right - Cue-left" waveforms. Asterisks indicate a significant difference between ipsilateral and contralateral waveforms in the corresponding half of the cue period.

observed among Valid, Neutral, and Invalid targets presented in the right side of space (all $p>0.11$ ).

Amplitude. A significant Group $\times$ Target side interaction was found $\left(F_{(2,37)}=3.8, p=0.03, \eta_{p}^{2}=0.17\right)$. Bonferroni post hoc comparisons showed that in $\mathrm{N}+$ the amplitude of the $\mathrm{P} 3 \mathrm{~b}$ was reduced in response to targets in the left side of space compared with those in the right side (left $=1.9 \mu \mathrm{V}$, right $3.3 \mu \mathrm{V}, p=$ $0.005)$. No comparable difference was observed in $\mathrm{HC}$ and $\mathrm{N}-$ (all $p>0.46)$. The Group $\times$ Trial type interaction was also significant $\left(F_{(4,74)}=2.9, p=0.04, \eta_{p}^{2}=0.13\right)$. This showed that the amplitude of the $\mathrm{P} 3 \mathrm{~b}$ was higher for Invalid compared with Valid and Neutral trials in $\mathrm{HC}$ (Invalid $=4.6 \mu \mathrm{V}$ vs Valid $=3.4 \mu \mathrm{V}, p=$ 0.005 ; Invalid $=4.6 \mu \mathrm{V}$ vs Neutral $=3.4 \mu \mathrm{V}, p=0.02$; Fig. 7). The same difference was not observed in $\mathrm{N}-$ and $\mathrm{N}+$ groups (all $p>0.33)$. All others main effects and interactions were not significant (all $F<2.3$, all $p>0.19$ ).

These results suggest that $\mathrm{N}+$ suffer defective processing and updating of the probabilistic occurrence of behaviorally relevant sensory events in the left side of space.

\section{Early target related components (P1 and N1) P1}

Latency. In line with the results of previous studies (Slagter et al., 2016; Lasaponara et al., 2017), a significant Group × Target side $\times$ Hemisphere triple interaction $\left(F_{(2,37)}=57.2, p=0.0000\right.$, $\left.\eta_{p}^{2}=0.75\right)$ highlighted that when targets were presented in the right side of space, the $\mathrm{P} 1$ recorded over the ipsilateral right hemisphere was delayed by $\sim 45-50 \mathrm{~ms}$ with respect to the $\mathrm{P} 1$ recorded over the left hemisphere (all $p$ values $=0.0000$ ). This result was present in all experimental groups (Fig. 8). In contrast, when targets were presented in the left side of space, the P1 recorded over the ipsilateral left hemisphere was delayed, with respect to its contralateral counterpart, by $45-50 \mathrm{~ms}$ in $\mathrm{HC}$ and $\mathrm{N}-$ (all $p$ values $=0.0000)$ though not in $\mathrm{N}+$. In $\mathrm{N}+$, a reversed latency pattern was found so that the $\mathrm{P} 1$ recorded over the contralateral right hemisphere followed by $\sim 60 \mathrm{~ms}$, rather than anticipated, the $\mathrm{P} 1$ recorded over the ipsilateral left hemisphere (197 ms vs $135 \mathrm{~ms} ; p=0.0000)$. In $\mathrm{N}+$ the latency of this contralateral P1 was also significantly longer than in $\mathrm{HC}$ (197 ms vs $120 \mathrm{~ms} ; p=$ $0.0000)$ and $\mathrm{N}-(197 \mathrm{~ms}$ vs $114 \mathrm{~ms} ; p=0.0000)$.

Amplitude. A significant Group $\times$ Target side $\times$ Hemisphere triple interaction $\left(F_{(2,37)}=7.1 p=0.002, \eta_{p}^{2}=0.27\right)$ showed that in all groups, targets presented in the right side of space evoked larger P1 amplitude over the ipsilateral right than over the contralateral left hemisphere (all $p$ values $<0.01$ ). When targets were presented in the left side of space, in HC the amplitude of the P1 was higher over the ipsilateral hemisphere (ipsilateral P1: $0.57 \mu \mathrm{V}$ 
RBD patients with neglect $(\mathrm{N}+)$

A
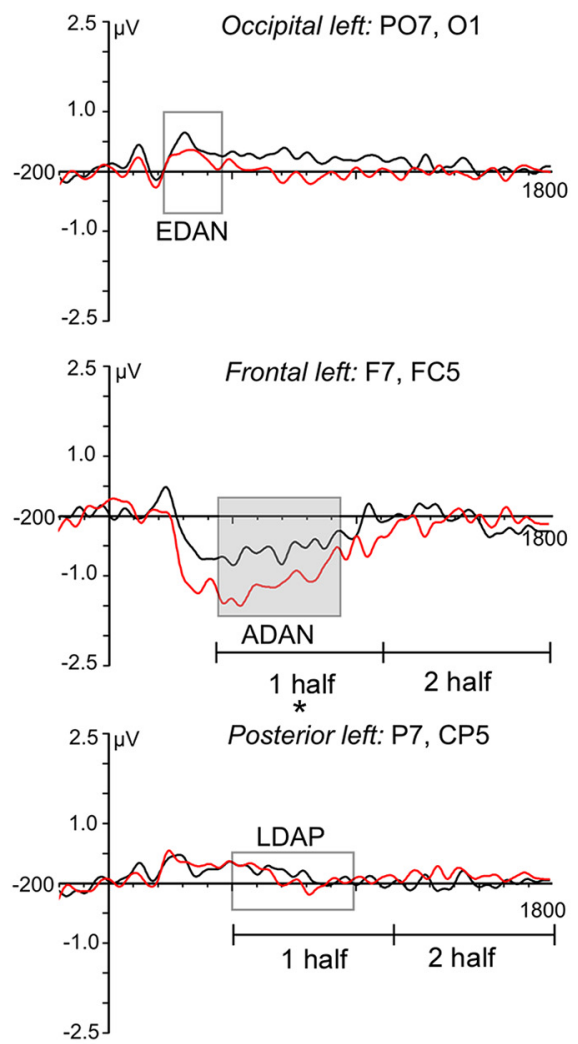
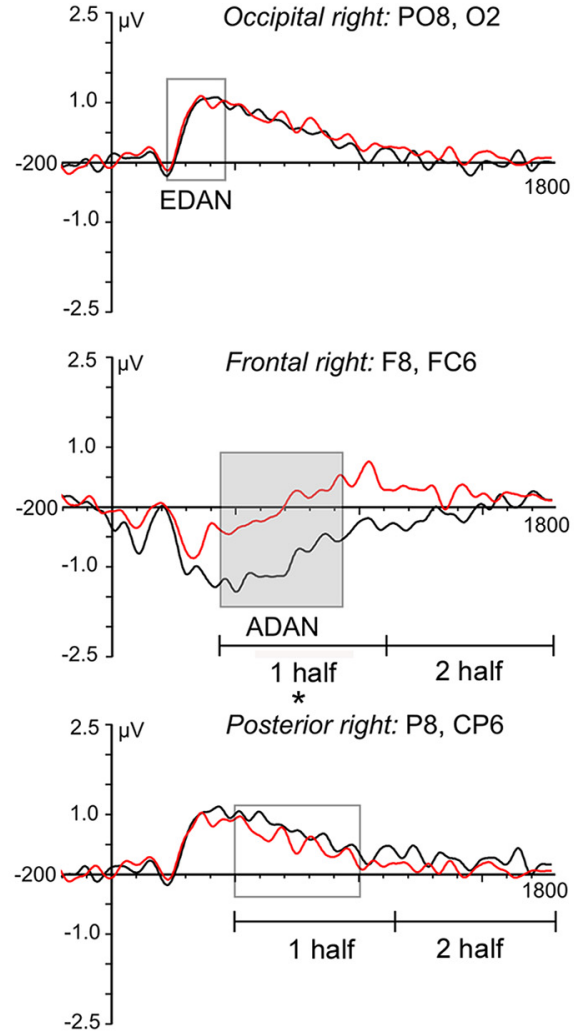

B
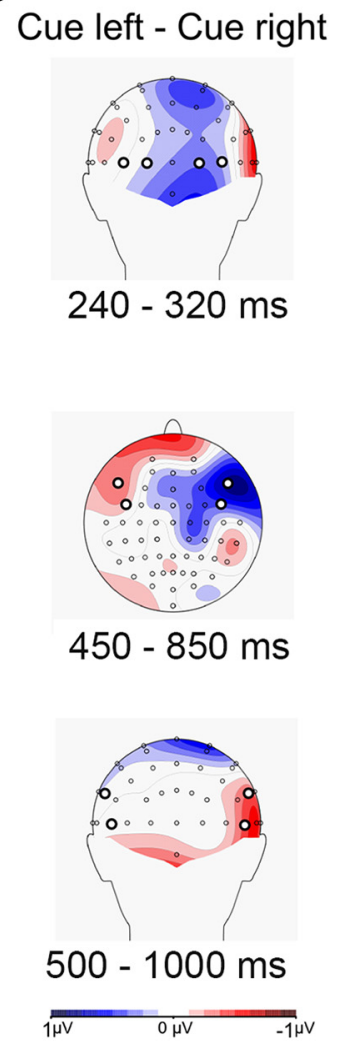

Cue left

Cue right

Figure 5. A, Cue-related ERP components recorded in RBD patients with left spatial neglect $(\mathrm{N}+$ ) during directional trials with arrow-cues pointing to the left (black line) or the right (red line). B, Scalp topographic maps representing the amplitude of differential "Cue-right - Cue-left" waveforms. Asterisks indicate a significant difference between ipsilateral and contralateral waveforms in the corresponding half of the cue period.

vs contralateral P1: $0.27 \mu \mathrm{V}, p=0.01$ ), whereas no significant difference between ipsilateral and contralateral P1 amplitude was found in $\mathrm{N}-$ (ipsilateral P1: $0.23 \mu \mathrm{V}$ vs contralateral $\mathrm{P} 1: 0.34 \mu \mathrm{V}$, $p=0.37)$. In $\mathrm{N}+$ the amplitude pattern was reversed and a larger P1 was found over the contralateral right hemisphere when targets were presented in the left side of space (ipsilateral P1: $0.22 \mu \mathrm{V}$ vs contralateral P1: $0.64 \mu \mathrm{V}, p=0.003$ ).

This set of analyses show that $\mathrm{N}+$ suffer reduced inhibition of sensory processing in the right space when targets occur in the left one.

\section{Valid minus Invalid difference waves (sensory gain)}

$t$ Tests revealed that independently of Target side and Hemisphere, in HC the amplitude of the differential P1 waveform between Valid and Invalid targets was significantly different from zero (all $t_{(14)}>4.8$, all $p<0.0002$ ). This shows conventional sensory gain in $\mathrm{HC}$. In $\mathrm{N}-$ differential waveforms were significantly different from zero only for right targets (both $t_{(12)}>2.8$, all $p<0.01$ ), whereas in $\mathrm{N}+$ no sensory gain was found for the P1 evoked by left or right targets (all $t_{(11)}<0.76$, all $p>0.45$ ). When individual differential waveforms were entered in a Group $(C$, $\mathrm{N}-, \mathrm{N}+$ ) $\times$ Target side (left, right) $\times$ Hemisphere (ipsilateral, contralateral) repeated-measures ANOVA, a significant Group $\times$ Target side interaction $\left(F_{(2,37)}=4.9 p=0.01, \eta_{p}^{2}=0.20\right)$ showed higher sensory gain in $\mathrm{HC}$ compared with both $\mathrm{N}-$ and $\mathrm{N}+$ in response to left targets $(\mathrm{HC}=0.41 \mu \mathrm{V}$ vs $\mathrm{N}-=0.03 \mu \mathrm{V}, p=$ $0.0008 ; \mathrm{HC}=0.41 \mu \mathrm{V}$ vs $\mathrm{N}+=0.06 \mu \mathrm{V}, p=0.002)$. No difference was found for left targets between $\mathrm{N}-$ and $\mathrm{N}+(\mathrm{N}-=0.03$ $\mu \mathrm{V}$ vs $\mathrm{N}+=0.06 \mu \mathrm{V}, p=0.79$ ). For right targets, sensory gain was higher in $\mathrm{HC}$ compared with $\mathrm{N}+(\mathrm{HC}=0.38 \mu \mathrm{V}$ vs $\mathrm{N}+=$ $0.14 \mu \mathrm{V}, p=0.03$ ), though no difference was found between $\mathrm{HC}$ and $\mathrm{N}-(\mathrm{HC}=0.38 \mu \mathrm{V}$ vs $\mathrm{N}-=0.45 \mu \mathrm{V}, p=0.47)$. For right targets $\mathrm{N}-$ showed higher sensory gain than $\mathrm{N}+(\mathrm{N}-=0.45 \mu \mathrm{V}$ vs $\mathrm{N}+=0.14 \mu \mathrm{V}, p=0.008)$. No effect of attentional cuing was found in the latency peaks of the P1 component (all $F<2.6$, all $p>0.12$ ).

\section{N1}

Latency

A significant Group $\times$ Target side interaction $\left(F_{(2,37)}=9.4, p=\right.$ $\left.0.0004, \eta_{p}^{2}=0.33\right)$ pointed out that in HC there was no latency difference between the $\mathrm{N} 1$ evoked by targets in the left or the right side of space (left target: $202.4 \mathrm{~ms}$ vs right target: $209 \mathrm{~ms}, p=$ 0.50 ). In contrast, in $\mathrm{N}-$ the $\mathrm{N} 1$ evoked by targets in the right side of space was slightly delayed compared with that evoked by targets in the left side (left target: $192.8 \mathrm{~ms}$ vs right target: $226.7 \mathrm{~ms}$, $p=0.02)$. In $\mathrm{N}+$, the $\mathrm{N} 1$ was found only over the left hemisphere in response to targets presented in the right side of space. The latency of this N1,215 ms, was equivalent to those found in $\mathrm{HC}$ and $\mathrm{N}-$. 
A

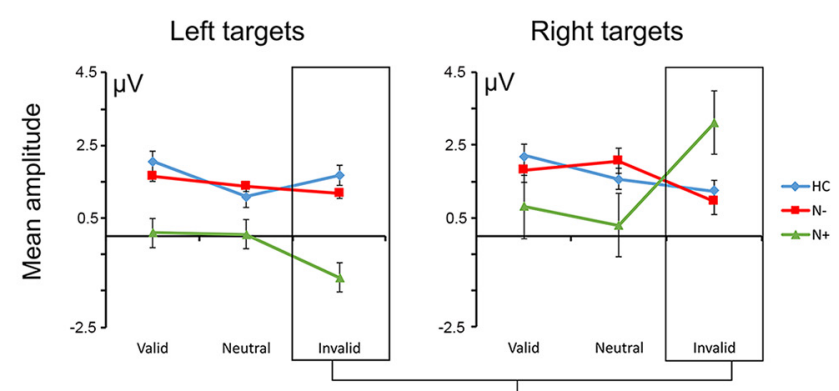

B

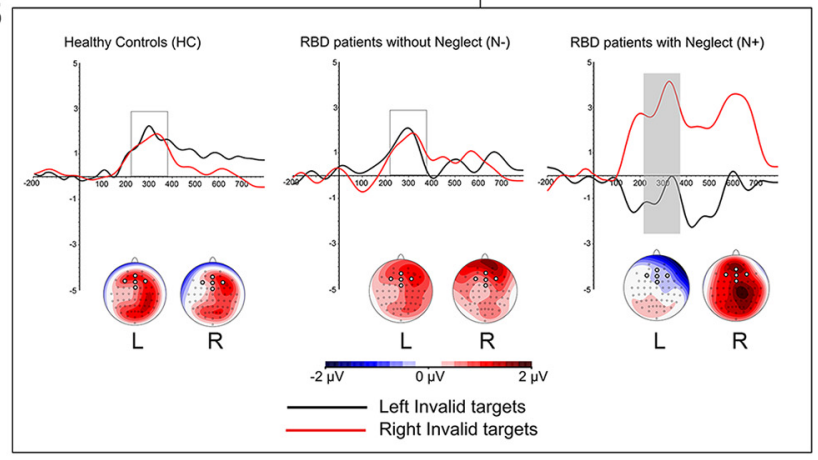

C
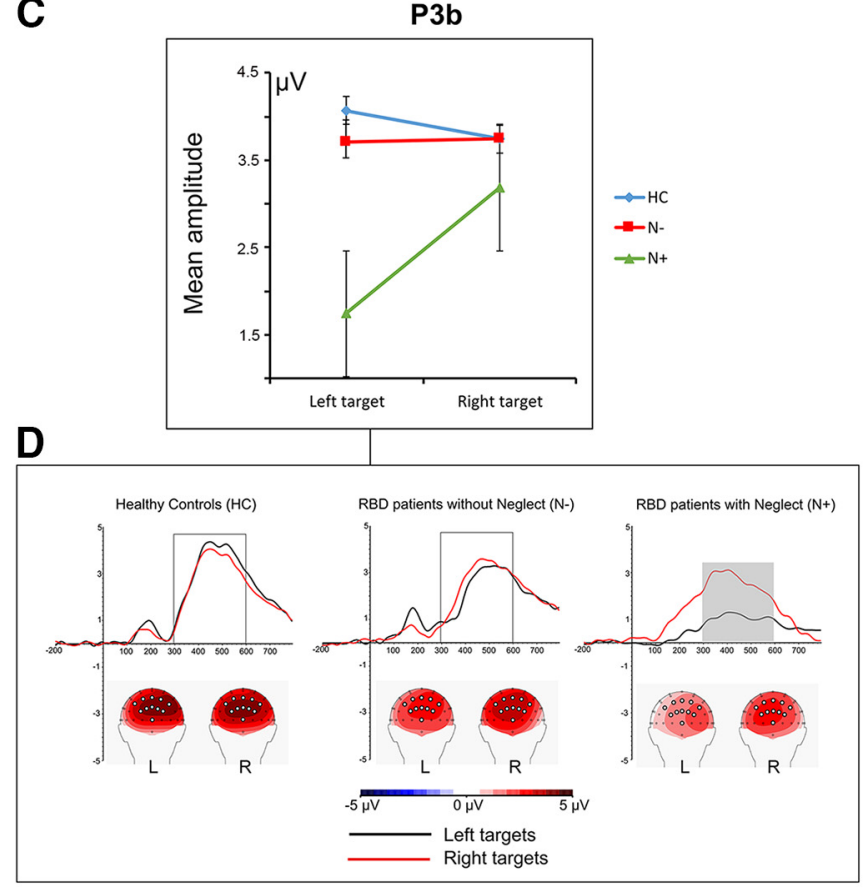

Figure 6. A, Mean amplitude of the P3a response to left and right Valid, Neutral, and Invalid targets in the three experimental groups (HC, N-, N+). Error bars indicate SE. B, Grand average of target-related ERPs in response to Invalid targets presented in the left (black) and in the right (red) side of space in the three experimental groups (HC, $\mathrm{N}-, \mathrm{N}+$ ). Time windows used for analyses are highlighted by gray squares (full squares = significant difference; empty squares = nonsignificant difference). $\boldsymbol{C}$, Mean amplitude of P3b responses to left and right targets in the three experimental groups $(\mathrm{HC}, \mathrm{N}-, \mathrm{N}+$ ). Error bars indicate $\mathrm{SE}$. $\boldsymbol{D}$, Grand average of P3b responses to targets presented in the left (black) and in the right (red) side of space in the three experimental groups $(\mathrm{HC}, \mathrm{N}-, \mathrm{N}+)$. Time windows used for analyses are highlighted by gray squares (full squares = significant difference; empty squares $=$ nonsignificant difference).

\section{Amplitude}

A significant Group effect $\left(F_{(2,37)}=15.8, p=0.0001, \eta_{p}^{2}=0.46\right)$ showed that the N1 was larger in $\mathrm{HC}$ compared with both $\mathrm{N}-$ and $\mathrm{N}+($ all $p$ values $<0.001)$. No negative peak was found in the $\mathrm{N} 1$ latency time window in $\mathrm{N}+$.

\section{Valid minus Invalid difference waves (sensory gain)}

In HC, the amplitude of the differential waveform between Valid and Invalid targets was significantly different from zero, independently of target side (both $t_{(14)}>-6.1$, all $p<0.0001$ ). In $\mathrm{N}-$ differential waveforms were significantly different from zero only in response to right targets $\left(t_{(12)}>-15.3\right.$, all $\left.p<0.0000\right)$. No significant differential waveforms were found in $\mathrm{N}+$ (both $t_{(11)}<$ 1.8 , both $p>0.1)$. When individual differential waveforms were entered in a Group $(\mathrm{C}, \mathrm{N}-, \mathrm{N}+) \times$ Target Side (left, right) repeated-measures ANOVA, a significant Group $\times$ Target side interaction $\left(F_{(2,37)}=3.3 p=0.04, \eta_{p}^{2}=0.15\right)$ showed larger differential waveforms in $\mathrm{HC}$ compared with both $\mathrm{N}-$ and $\mathrm{N}+$ in response to left targets $(\mathrm{HC}=-1.1 \mu \mathrm{V}$ vs $\mathrm{N}-=-0.03 \mu \mathrm{V}$, $p=0.000 ; \mathrm{HC}=-1.1 \mu \mathrm{V}$ vs $\mathrm{N}+=0.32 \mu \mathrm{V}, p=0.000)$. No significant difference was found between $\mathrm{N}-$ and $\mathrm{N}+(\mathrm{N}-=$ $-0.03 \mu \mathrm{V}$ vs $\mathrm{N}+=0.32 \mu \mathrm{V}, p=0.06)$. Also in the case of right targets, differential waveforms were larger in $\mathrm{HC}$ compared with both $\mathrm{N}+(\mathrm{HC}=-1.5 \mu \mathrm{V}$ vs $\mathrm{N}+=0.18 \mu \mathrm{V}, p=0.000)$ and $\mathrm{N}-$ $(\mathrm{HC}=1.5 \mu \mathrm{V}$ vs $\mathrm{N}-=-0.93 \mu \mathrm{V}, p=0.0008)$. Nonetheless, at variance with left targets, $\mathrm{N}$ - showed larger differential waveforms in response to right targets compared with $\mathrm{N}+(\mathrm{N}-=$ $-0.93 \mu \mathrm{V}$ vs $\mathrm{N}+=0.18 \mu \mathrm{V}, p=0.000)$. Valid attentional cuing produced no change in the latency peaks of the N1 component (all $F<1$ and all $p>0.35$; (Fig. 9)).

\section{Caveats on the interpretation of ERP findings in brain-damaged patients}

A full interpretation of ERP modifications after brain damage would imply establishing the roles played by the anatomical/ functional disruption of ERP neural sources and/or by the altered propagation of normally generated EEG signals through the damaged neural tissue. This is a largely open issue. A few modeling studies (Cohen et al., 2015) have suggested that ischemic stroke should induce higher resistivity in damaged neural tissue resulting in higher potentials in the damaged compared with the healthy hemisphere. Hemorrhagic strokes should induce lower resistivity in the damaged tissue and lower potential in the damaged hemisphere. In addition, it is also important to note that although some cortical areas play a primary role in the production of specific ERP components, most components arise from the joint activation of multiple secondary cortical sources (Linden, 2005). Thus a cautious interpretation of defective ERP components in our sample of patients is that brain damage modified specific ERP components either by disrupting, anatomically or functionally, the activity of their corresponding main generators and/or by disturbing the coordinate activation of multiple ERP sources. For exploratory purposes, based on available reviews of the literature, we have superimposed the coordinates of the sources of the different ERP components examined in the present study, on the lesion maps of $\mathrm{N}-$ and $\mathrm{N}+$ participants. The only potentially relevant finding of this purely exploratory investigation is that the portion of the insular cortex that participate as a secondary source in the generation of the P3A (Bledowski et al., 2004) was lesioned in 55\% of $\mathrm{N}+$ patients, whereas no lesion involvement was found in $\mathrm{N}-$. In contrast, in both groups there was an equal $20 \%$ lesion involvement of the inferior parietal gen- 
A

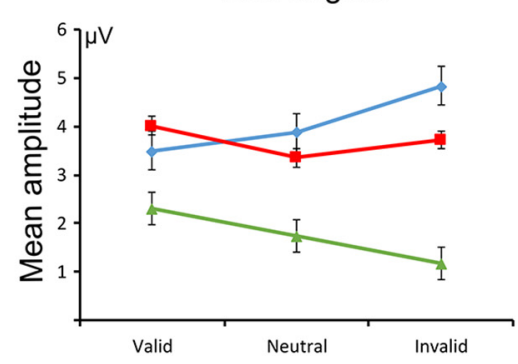

B
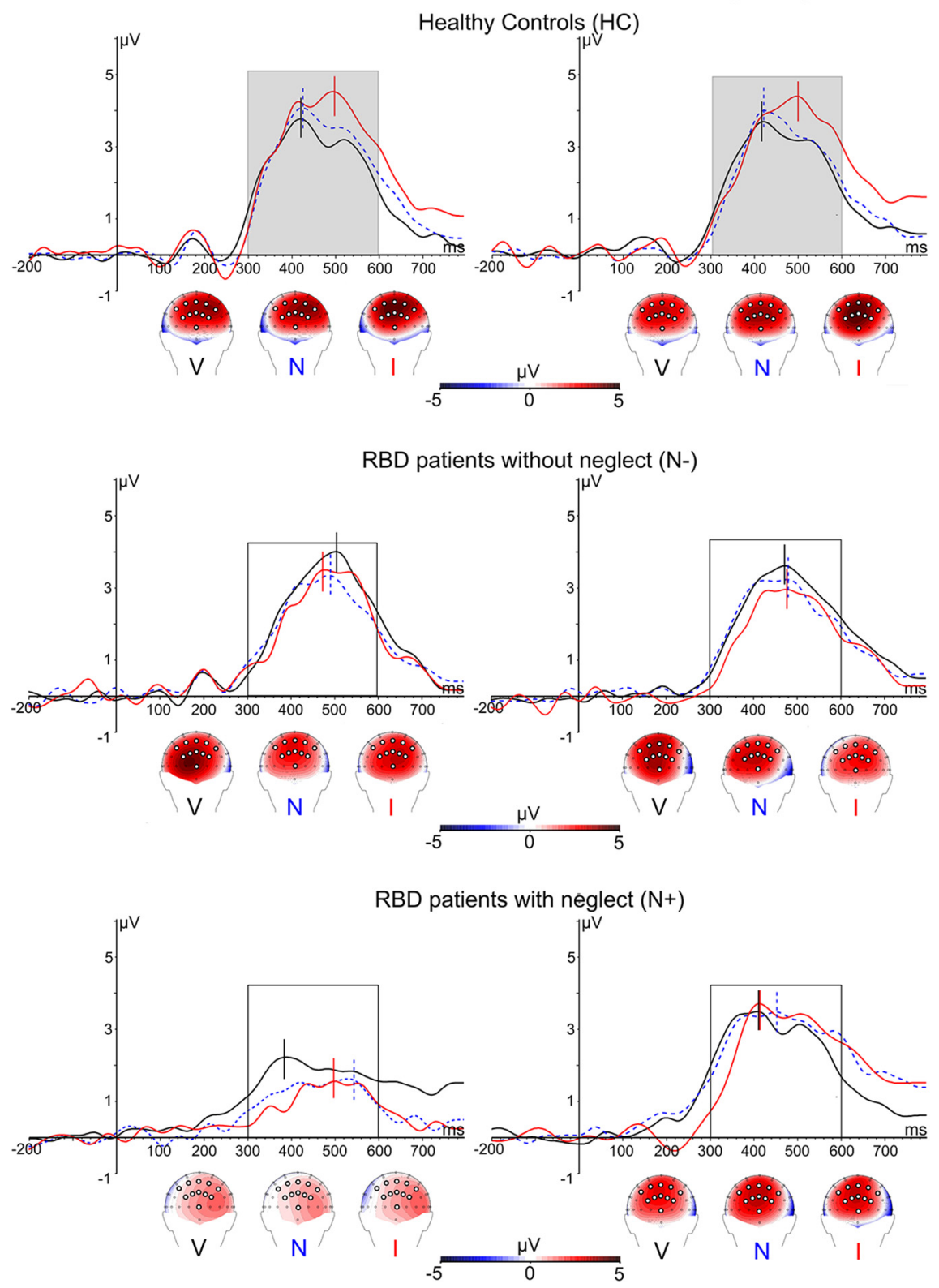

Figure 7. A, Mean amplitude of the P3b responses to left and right Valid, Neutral, and Invalid targets in the three experimental groups ( $\mathrm{HC}, \mathrm{N}-, \mathrm{N}+$ ). Error bars indicate SE. B, Grand average of target-related ERPs in response to Valid (black), Neutral (dashed blue), and Invalid (red) targets presented in the left and in the right side of space in the three experimental groups $(\mathrm{HC}, \mathrm{N}-, \mathrm{N}+$ ). Time windows used for analyses are highlighted by gray squares (full squares = significant difference; empty squares = nonsignificant difference). Vertical bars represent latency peaks estimated through the semiautomatic peak detection algorithm (see Materials and Methods). erators of the P3b, despite larger disruption of the P3b response to left targets in $\mathrm{N}+$, and an equivalent $10 \%$ lesion involvement of precentral areas participating in the generation of the ADAN (Praamstra et al., 2005), which was maintained in both groups. These preliminary observations suggest that both direct damage of cortical ERP sources and disturbed interaction among different cortical areas should be considered in interpreting alterations of ERPs after brain damage.

\section{Discussion}

\section{Preparatory orienting of attention:} cue-related responses

The first new finding of our study is that during preparatory voluntary orienting of attention $\mathrm{N}+$ patients show normal ADAN over frontal derivations in both hemispheres together with a complete bilateral drop of the LDAP over posterior occipital derivations. ERP studies have pointed out that the ADAN develops independently of sensory modality, thus marking an amodal mechanism of attention. In contrast, the LDAP develops in response to visual stimuli or to the use of visual references (Eimer, 2014): this is suggested by the absence of the LDAP in congenitally blind participants (Van Velzen et al., 2006) and during tactile attention tasks (Gherri et al., 2016). Our data show that amodal preparatory attentional engagement is preserved in $\mathrm{N}+$ though this is not followed by the setting-up of corresponding facilitatory effects in posterior visual areas. This dissociation sheds light on the functional basis of dissociations that past investigations in neglect have documented both in the study of reflexive and voluntary orienting and in the effects of different rehabilitation protocols. Several authors have argued that compared with deficits in reflexive orienting, $\mathrm{N}+$ would have relatively spared voluntary orienting of attention that can be exploited for rehabilitation (for review, Bartolomeo and Chokron, 2002; Natale et al., 2005). Natale et al. (2005) offered a more articulated view of this by showing that when targets are presented at a fixed position in left space, so as to favor the exploitation of such regularity and the voluntary focusing of attention at this position, $\mathrm{N}+$ show faster RTs to detected targets though no change in the frequency of hits and misses compared with targets presented at variable positions. The authors concluded that although voluntary orienting of attention can be relatively preserved in neglect patients, this produces no effect on 

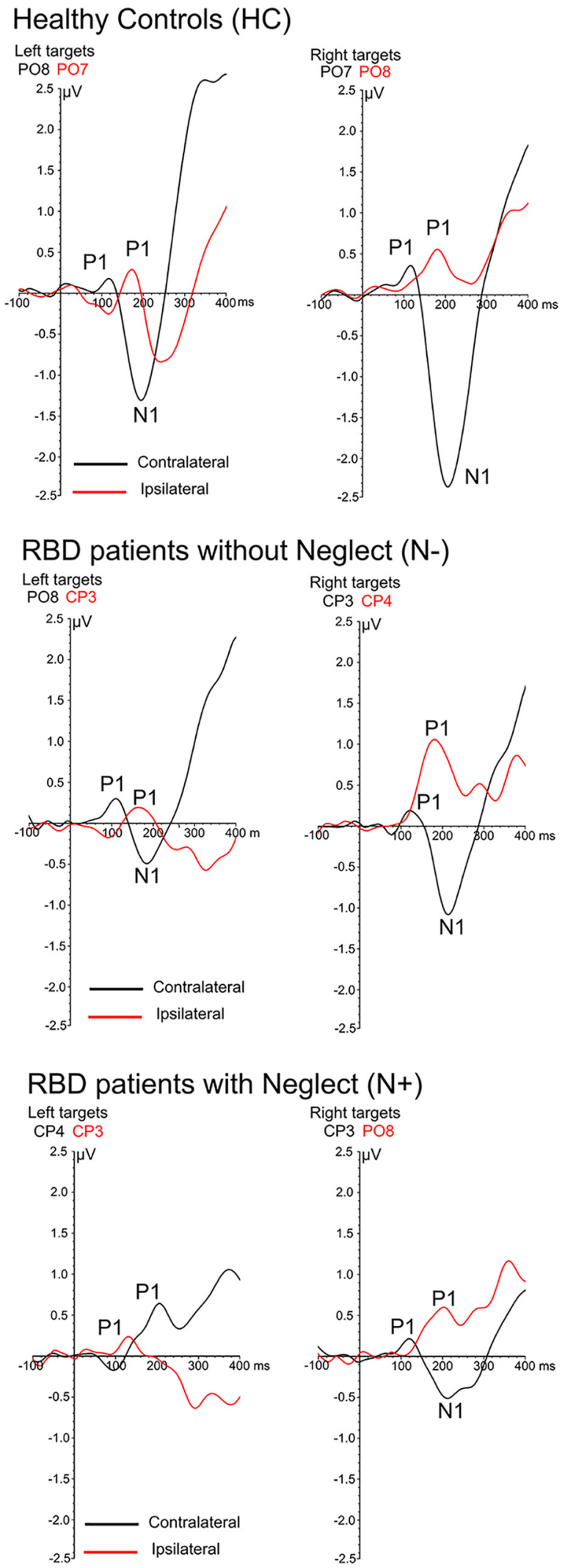

Figure 8. Grand average of early P1 and N1components recorded over the left and over the right hemisphere in response to ipsilateral (red) or contralateral (black) left and right targets. Top, Healthy controls; middle, RBD patients without left spatial neglect $(\mathrm{N}-)$; bottom, RBD patients with left spatial neglect $(\mathrm{N}+)$. Note that, at variance with the other groups, in $\mathrm{N}+$ the $P 1$ recorded over the contralateral right hemisphere in response to left targets (bottom left) follows, rather than foregoes, the $P 1$ recorded over the ipsilateral left hemisphere. their basic reflexive visual spatial deficits. The ADAN/LDAP dissociation that we have documented in our study clarifies the functional basis of the findings by Natale et al. (2005) and supports their conclusions. Sturm and coworkers (Sturm et al., 2006; Thimm et al., 2006, 2008) have demonstrated that although neglect rehabilitation through visual optokinetic stimulation produces a significant enhancement of the BOLD response in posterior visual areas, i.e., cuneus, rehabilitation focused on the voluntary management of attention enhances activation in frontal areas with no equivalent effects on posterior visual ones. Our results highlight a similar functional independence between frontal and posterior components of attentional orienting and suggest that rehabilitation of voluntary attention in $\mathrm{N}+$ might be ineffective unless associated with sensory stimulation boosting the response of posterior attentional visual areas. $\mathrm{N}+$ also showed a bilateral drop of the EDAN: this finding could highlight a general slowing of attentional reactivity in lateral orienting (Harter et al., 1989; Nobre et al., 2000) or in the selection and analysis of task-relevant features in central cues (Van Velzen and Eimer, 2003). The bilateral drop of the EDAN is in line with the presence of non-spatially lateralized deficit of attention in spatial neglect (Husain et al., 1997). To summarize, concomitant preservation of the ADAN and suppression of the EDAN and LDAP in spatial neglect suggests relevant functional independence among anterior and posterior preparatory components of attention that are related to the use of central spatial cues. Current studies in healthy participants point out that the ADAN can develop without the ensuing development of the LDAP (Gherri et al., 2016) but whether a normal development of the LDAP over the posterior extrastriate cortex must be necessarily preceded by the ADAN, remains to be explored.

Interestingly, $\mathrm{N}-$ patients showed normal bilateral ADAN and LDAP, although over the left hemisphere the onset of the LDAP was delayed to the second part of the cue period. One plausible interpretation of the faster development of the LDAP over the damaged hemisphere is that it reflected compensatory mechanism counteracting residual contralesional attentional deficits. In $\mathrm{N}-$, these residual deficits were evident both during the processing of central cues, when a drop of the EDAN over the right hemisphere was present and at the moment of target detection when $\mathrm{N}$ - showed a higher number of left target omissions compared with healthy controls.

Anatomical findings confirmed the role of parietal-frontal white-matter disconnection in the pathogenesis of spatial neglect (Doricchi and Tomaiuolo, 2003; Thiebaut de Schotten et al., 2005; Verdon et al., 2010). Poor parietal-frontal connectivity can probably account for the ADAN/ LDAP and ADAN/EDAN uncouplings that we have specifically highlighted in $\mathrm{N}+$. In addition, hypo-activation of subcortical structures adjacent to the damage like the pulvinar, might also contribute to reduced attentional modulation of preparatory responses in the visual areas (Green et al., 2017).

\section{Target related responses: late attentional processing and contextual updating}

In $\mathrm{N}+$ the $\mathrm{P} 3$ a recorded over frontal derivations was abnormally reduced in response to infrequent invalid targets in the left side of space and abnormally enhanced in response to equivalent targets in the right side. At variance with the P3a, the P3b component was reduced for all types of targets presented in the left side of space though not enhanced for those in the right side of space. This shows that $\mathrm{N}+$ suffer downregulation of novelty detection (P3a) and contextual updating (P3b) for events in the left side of 
A

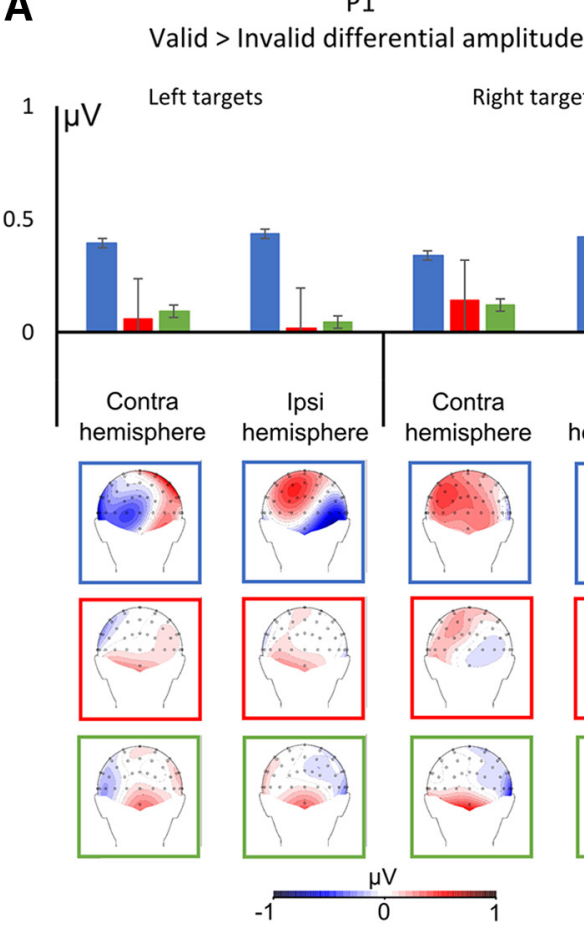

B

N1

Valid $>$ Invalid differential amplitude

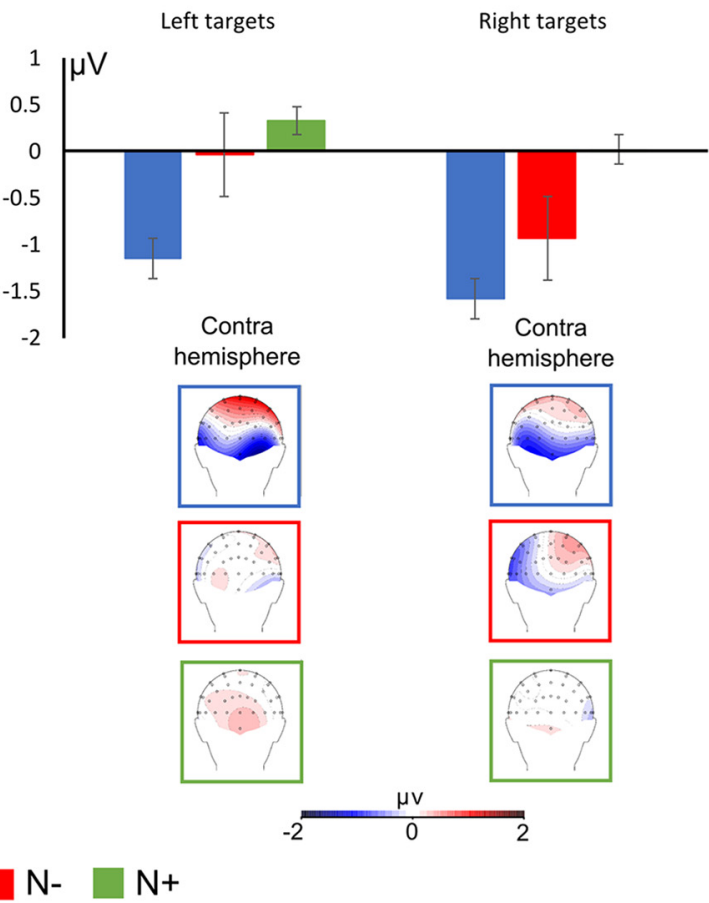

Figure 9. A, Mean Valid $>$ Invalid differential amplitude and relative scalp topographies, of the P1 component evoked by the left and the right targets over the ipsilateral and contralateral hemisphere in the healthy controls (HC; blue), RBD patients with left spatial neglect ( $\mathrm{N}+$; green) and patients without neglect ( $\mathrm{N}-$; red). Error bars indicate SE. B, Mean Valid $>$ Invalid differential amplitude and relative scalp topographies, of the $\mathrm{N} 1$ component evoked by the left and the right targets over the contralateral hemisphere in the healthy controls (HC; blue), RBD patients with left spatial neglect ( $\mathrm{N}+$; green), and patients without neglect ( $\mathrm{N}-$; red). Error bars indicate SE.

space and upregulation of novelty detection with normal contextual updating for events in the right side. This deficits might importantly contribute to the reduced interest of $\mathrm{N}+$ for events in the contralesional space and suggest the importance of investigating further whether $\mathrm{N}+$ can learn and exploit contextual contingencies that govern the distribution in space of behavioral targets (Bartolomeo et al., 2001; Geng and Behrmann, 2002) and rewards (Malhotra et al., 2013; Lecce et al., 2015).

Concomitant downregulation of the $\mathrm{P} 3 \mathrm{a}$ in response to left targets and upregulation in response to right ones suggests pushpull interhemispheric competition, whereas in the case of the P3b only selective contralesional downregulation was found. Differences in competitive hemispheric processing might be rooted in different patterns of interhemispheric connectivity, though available anatomical evidence does not yet provide sufficient evidence in favor of this conclusion (Catani and Thiebaut de Schotten, 2012; Caminiti et al., 2013; Joliot et al., 2015). Different spatial preferences of the cortical areas implicated in the generation of the P3a and P3b might also contribute to different types of interhemispheric competition. In humans, the right inferior frontal gyrus/middle frontal gyrus is sensitive to the novelty of invalidly cued targets though no lateral spatial preference is currently reported in this area (Shulman et al., 2009; Doricchi et al., 2010). In contrast, we have recently demonstrated that the left TPJ responds preferentially to invalid targets in the right side of space (Dragone et al., 2015; Silvetti et al., 2016). This spatial preference might determine the selective downregulation of the P3b response to targets in the left side of space after RBD. Downregulation of electrophysiological responses mediated by the frontal lobes, i.e., $\mathrm{P} 3 \mathrm{a}$, to contralesional stimuli and upregulation of responses to ipsilesional ones is also in line with a number of previous observations. Vuilleumier et al. (1996) have described sudden remission of left spatial neglect due to an initial right parietal stroke when a second stroke in the frontal area of the left hemisphere reduced the ipsilesional bias caused by the first stroke. Reduction of ipsilesional hyper-attention in neglect is also produced by TMS inactivation of the left frontal cortex (Oliveri et al., 1999). More recently, Rastelli et al. (2013) showed that in patients with left spatial neglect omissions of visual targets in the left side of space is systematically anticipated by upregulated synchronization of beta MEG activity over frontal areas in the left hemisphere. The results of our study expand on this evidence and show that interhemispheric push-pull competitive mechanisms also affect the late phases of attentional processing reflected in $\mathrm{P} 3 \mathrm{a}$ and $\mathrm{P} 3 \mathrm{~b}$ responses.

Target related responses: early attentional processing and the P1-related inhibition of the unstimulated side of space Comparisons between $\mathrm{P} 1$ and N1 components evoked by valid and invalid targets, demonstrated bilateral loss of sensory gain produced by valid cuing in $\mathrm{N}+$ and loss of sensory gain for targets appearing in the left side of space in $\mathrm{N}-$. It is interesting to note that in $\mathrm{N}+$ bilateral drop of sensory gain was matched with bilateral drop of cue-related preparatory EDAN and LDAP components over posterior visual areas, whereas in $\mathrm{N}-$ preserved gain for targets in the right side of space was matched with preserved EDAN and LDAP over the left hemisphere. In contrast, in $\mathrm{N}-$ loss of sensory gain for targets in the left side of space was matched with preserved LDAP and loss of EDAN on the right hemisphere. Whether this finding suggests that normal develop- 
ment of sensory gain in the processing of visual targets depends on maintenance of both EDAN and LDAP preparatory components remains matter for future investigations.

Like in previous studies (Verleger et al., 1996; Deouell et al., 2000; Di Russo et al., 2008), in N+ we found suppression of the $\mathrm{N} 1$ and preservation of the P1 component evoked by left side targets over the right hemisphere. In line with the data by Slagter et al. (2016), in healthy controls the P1 appeared first over the hemisphere contralateral to the target and then in that ipsilateral to the target where it displayed greater amplitude. In contrast, in $\mathrm{N}+$ the hemispheric distribution in the amplitude and latency of the P1 evoked by left side targets was entirely altered. In this case the P1 evoked over the ipsilateral left hemisphere was smaller, rather than larger, and anticipated, rather than followed, the P1 recorded over the contralateral right hemisphere. This finding points out concomitant delayed response to validly cued targets in contralesional left side of space and poor target-related inhibition in the sensory processing of the unstimulated ipsilesional right side. This pattern in the hemispheric distribution of the P1 response identifies a new electrophysiological marker of hyperattention for the right side of space in spatial neglect and shows further that voluntary engagement of attention does not entirely counteract basic deficits in the automatic processing of contralesional targets (Bartolomeo et al., 2001; Natale et al., 2005). The reduction in the amplitude of the $\mathrm{P} 1$ evoked over the left hemisphere by left side targets was also matched with a relative reduction of its latency and with a relative increase in the latency of the P1 over the right hemisphere. Future studies should clarify whether these changes in the latency of $\mathrm{P} 1$ are linked to pathological changes in callosal connectivity (Slagter et al., 2016; Lasaponara et al., 2017), which can be anatomically and functionally disrupted in neglect patients (Lunven et al., 2015). In line with our findings, in a recent ERP study Martín-Arévalo et al. (2016) demonstrated that in healthy humans adaptation to leftwarddeviating prismatic lenses produces left spatial neglect-like behaviors together with a reduction in the amplitude of the left hemispheric P1 response to left side targets.

In conclusion, the results of our study provide new insights on the attentional impairments suffered by $\mathrm{N}+$ and suggest that in the healthy brain the components of preparatory attention mediated by frontal and parietal-occipital areas have a degree of functional independency.

\section{References}

Albert ML (1973) A simple test of visual neglect. Neurology 23:658-664. CrossRef Medline

Azouvi P, Samuel C, Louis-Dreyfus A, Bernati T, Bartolomeo P, Beis JM, Chokron S, Leclercq M, Marchal F, Martin Y, De Montety G, Olivier S, Perennou D, Pradat-Diehl P, Prairial C, Rode G, Siéroff E, Wiart L, Rousseaux M; French Collaborative Study Group on Assessment of Unilateral Neglect (GEREN/GRECO) (2002) Sensitivity of clinical and behavioural tests of spatial neglect after right hemisphere stroke. J Neurol Neurosurg Psychiatry 73:160-166. CrossRef Medline

Bartolomeo P, Chokron S (2002) Orienting of attention in left unilateral neglect. Neurosci Biobehav Rev 26:217-234. CrossRef Medline

Bartolomeo P, Siéroff E, Decaix C, Chokron S (2001) Modulating the attentional bias in unilateral neglect: the effects of the strategic set. Exp Brain Res 137:432-444. CrossRef Medline

Bartolomeo P, Thiebaut de Schotten M, Doricchi F (2007) Left unilateral neglect as a disconnection syndrome. Cereb Cortex 17:2479-2490. CrossRef Medline

Bledowski C, Prvulovic D, Hoechstetter K, Scherg M, Wibral M, Goebel R, Linden DE (2004) Localizing P300 generators in visual target and distractor processing: a combined event-related potential and functional magnetic resonance imaging study. J Neurosci 24:9353-9360. CrossRef Medline
Caminiti R, Carducci F, Piervincenzi C, Battaglia-Mayer A, Confalone G, Visco-Comandini F, Pantano P, Innocenti GM (2013) Diameter, length, speed, and conduction delay of callosal axons in macaque monkeys and humans: comparing data from histology and magnetic resonance imaging diffusion tractography. J Neurosci 33:14501-14511. CrossRef Medline

Catani M, Thiebaut de Schotten M (2012) Commisural pathways. In: Atlas of human brain connections, pp 343-378. New York, NY: Oxford UP.

Cohen R, Abboud S, Arad M (2015) Monitoring brain damage using bioimpedance technique in a 3D numerical model of the head. Med Eng Phys 37:453-459. CrossRef Medline

Curran T, Hills A, Patterson MB, Strauss ME (2001) Effects of aging on visuospatial attention: an ERP study. Neuropsychologia 39:288-301. CrossRef Medline

Daffner KR, Mesulam MM, Scinto LF, Acar D, Calvo V, Faust R, Chabrerie A, Kennedy B, Holcomb P (2000) The central role of the prefrontal cortex in directing attention to novel events. Brain 123:927-939. CrossRef Medline

Daffner KR, Scinto LFM, Weitzman AM, Faust R, Rentz DM, Budson AE, Holcom, PJ (2003) Frontal and parietal components of a cerebral network mediating voluntary attention to novel events. J Cogn Neurosci 15:294313. CrossRef

Deouell LY, Bentin S, Soroker N (2000) Electrophysiological evidence for an early (pre-attentive) information processing deficit in patients with right hemisphere damage and unilateral neglect. Brain 123:353-365. CrossRef Medline

Diller L, Weinberg J, Gordon W, Goodkin R, Gerstman LJ, Ben-Yishay Y (1974) Studies in cognition and rehabilitation in hemiplegia. New York, NY: Behavioral Science, Institute of Rehabilitation Medicine, New York University Medical Center.

Di Russo F, Aprile T, Spitoni G, Spinelli D (2008) Impaired visual processing of contralesional stimuli in neglect patients: a visual-evoked potential study. Brain 131:842-854. CrossRef Medline

Doricchi F, Tomaiuolo F (2003) The anatomy of neglect without hemianopia: a key role for parietal-frontal disconnection? Neuroreport 14:22392243. CrossRef Medline

Doricchi F, Thiebaut de Schotten M, Tomaiuolo F, Bartolomeo P (2008) White matter (dis) connections and gray matter (dys) functions in visual neglect: gaining insights into the brain networks of spatial awareness. Cortex 44:983-995. CrossRef Medline

Doricchi F, Macci E, Silvetti M, Macaluso E (2010) Neural correlates of the spatial and expectancy components of endogenous and stimulus-driven orienting of attention in the posner task. Cereb Cortex 20:1574-1585. CrossRef Medline

Dragone A, Lasaponara S, Silvetti M, Macaluso E, Doricchi F (2015) Selective reorienting response of the left hemisphere to invalid visual targets in the right side of space. Cortex 65:31-35. CrossRef Medline

Eimer M (2014) The time course of spatial attention: insights from eventrelated brain potentials. In: The Oxford handbook of attention, (Nobre AC, Kastner S, eds) pp 289-317. Oxford Handbooks Online: Oxford UP. CrossRef

Eimer M, van Velzen J, Driver J (2002) Cross-modal interactions between audition, touch, and vision in endogenous spatial attention: ERP evidence on preparatory states and sensory modulations. J Cogn Neurosci 14:254271. CrossRef Medline

Flores AB, Gómez CM, Meneres S (2010) Evaluation of spatial validityinvalidity by the P300 component in children and young adults. Brain Res Bull 81:525-533. CrossRef Medline

Geng JJ, BehrmannM (2002) Probability cuing of target location facilitates visual search implicitly in normal participants and patients with hemispatial neglect. Psychol Sci 13:520-525 CrossRef Medline

Gherri E, Gooray E, Forster B (2016) Cue-locked lateralized components in a tactile spatial attention task: evidence for a functional dissociation between ADAN and LSN. Psychophysiology 53:507-517. CrossRef Medline

Gomez Gonzalez CM, Clark VP, Fan S, Luck SJ, Hillyard SA (1994) Sources of attention-sensitive visual event-related potentials. Brain Topogr 7:4151. CrossRef Medline

Gratton G, Coles MG, Donchin E (1983) A new method for off-line removal of ocular artifact. Electroencephalogr Clin Neurophysiol 55:468-484. CrossRef Medline

Green JJ, Boehler CN, Roberts KC, Chen LC, Krebs RM, Song AW, Woldorff 
MG (2017) Cortical and subcortical coordination of visual spatial attention revealed by simultaneous EEG-fMRI recording. J Neurosci 37:78037810. CrossRef Medline

Halligan P, Wilson B, Cockburn J (1990) A short screening test for visual neglect in stroke patients. Int Disabil Stud 12:95-99. CrossRef Medline

Harter MR, Miller SL, Price NJ, Lalonde ME, Keyes AL (1989) Neural processes involved in directing attention. J Cogn Neurosci 1:223-237. CrossRef Medline

Hillyard SA, Vogel EK, Luck SJ (1998) Sensory gain control (amplification) as a mechanism of selective attention: electrophysiological and neuroimaging evidence. Philos Trans R Soc Lond B Biol Sci 353:1257-1270. CrossRef Medline

Hopf JM, Mangun GR (2000) Shifting visual attention in space: an electrophysiological analysis using high spatial resolution mapping. Clin Neurophysiol 111:1241-1257. CrossRef Medline

Husain M, Rorden C (2003) Non-spatially lateralized mechanisms in hemispatial neglect. Nat Rev Neurosci 4:26-36. CrossRef Medline

Husain M, Shapiro K, Martin J, Kennard C (1997) Abnormal temporal dynamics of visual attention in spatial neglect patients. Nature 385:154-156. CrossRef Medline

Joliot M, Jobard G, Naveau M, Delcroix N, Petit L, Zago L, Crivello F, Mellet E, Mazoyer B, Tzourio-Mazoyer N (2015) AICHA: an atlas of intrinsic connectivity of homotopic areas. J Neurosci Methods 254:46-59. CrossRef Medline

Kelly SP, Gomez-Ramirez M, Foxe JJ (2009) The strength of anticipatory spatial biasing predicts target discrimination at attended locations: a high-density EEG study. Eur J Neurosci 30:2224-2234. CrossRef Medline

Kelly SP, Foxe JJ, Newman G, Edelman JA (2010) Prepare for conflict: EEG correlates of the anticipation of target competition during overt and covert shifts of visual attention. Eur J Neurosci 31:1690-1700. CrossRef Medline

Lasaponara S, Chica AB, Lecce F, Lupianez J, Doricchi F (2011) ERP evidence for selective drop in attentional costs in uncertain environments: challenging a purely premotor account of covert orienting of attention. Neuropsychologia 49:2648-2657. CrossRef Medline

Lasaponara S, D’Onofrio M, Dragone A, Pinto M, Caratelli L, Doricchi F (2017) Changes in predictive cuing modulate the hemispheric distribution of the P1 inhibitory response to attentional targets. Neuropsychologia 99:156-164. CrossRef Medline

Lecce F, Rotondaro F, Bonnì S, Carlesimo A, Thiebaut de Schotten M, Tomaiuolo F, Doricchi F (2015) Cingulate neglect in humans: disruption of contralesional reward learning in right brain damage. Cortex 62:73-88. CrossRef Medline

Lhermitte F, Turell E, LeBrigand D, Chain F (1985) Unilateral visual neglect and wave P 300: a study of nine cases with unilateral lesions of the parietal lobes. Arch Neurol 42:567-573. CrossRef Medline

Linden DE (2005) The P300: where in the brain is it produced and what does it tell us? Neuroscientist 11:563-576. CrossRef Medline

Lunven M, Thiebaut de Schotten M, Bourlon C, Duret C, Migliaccio R, Rode G, Bartolomeo P (2015) White matter lesional predictors of chronic visual neglect: a longitudinal study. Brain 138:746-760. CrossRef Medline

Macaluso E, Doricchi F (2013) Attention and predictions: control of spatial attention beyond the endogenous-exogenous dichotomy. Front Hum Neurosci 7:685. CrossRef Medline

Malhotra PA, Soto D, Li K, Russell C (2013) Reward modulates spatial neglect. J Neurol Neurosurg Psychiatry 84:366-369. CrossRef Medline

Mangun GR, Hillyard SA (1991) Modulations of sensory-evoked brain potentials indicate changes in perceptual processing during visual-spatial priming. J Exp Psychol Hum Percept Perform 17:1057-1074. CrossRef Medline

Martín-Arévalo E, Laube I, Koun E, Farnè A, Reilly KT, Pisella L (2016) Prism adaptation alters electrophysiological markers of attentional processes in the healthy brain. J Neurosci 36:1019-1030. CrossRef Medline

Massironi M, Antonucci G, Pizzamiglio L, Vitale MV, Zoccolotti P (1988) The Wundt-Jastrow illusion in the study of spatial hemi-inattention. Neuropsychologia 26:161-166. CrossRef Medline

Mort DJ, Malhotra P, Mannan SK, Rorden C, Pambakian A, Kennard C, Husain M (2003) The anatomy of visual neglect. Brain 126:1986-1997. CrossRef Medline

Natale E, Posteraro L, Prior M, Marzi CA (2005) What kind of visual spatial attention is impaired in neglect? Neuropsychologia 43:1072-1085. CrossRef Medline

Nobre AC, Sebestyen GN, Miniussi C (2000) The dynamics of shifting visuospatial attention revealed by event-related potentials. Neuropsychologia 38:964-974. CrossRef Medline

Oishi K, Zilles K, Amunts K, Faria A, Jiang H, Li X, Akhter K, Hua K, Woods R, Toga AW, Pike GB, Rosa-Neto P, Evans A, Zhang J, Huang H, Miller MI, van Zijl PC, Mazziotta J, Mori S (2008) Human brain white matter atlas: identification and assignment of common anatomical structures in superficial white matter. Neuroimage 43:447-457. CrossRef Medline

Oliveri M, Rossini PM, Traversa R, Cicinelli P, Filippi MM, Pasqualetti P, Tomaiuolo F, Caltagirone C (1999) Left frontal transcranial magnetic stimulation reduces contralesional extinction in patients with unilateral right brain damage. Brain 122:1731-1739. CrossRef Medline

Pizzamiglio L, Antonucci G, Judica A, Montenero P, Razzano C, Zoccolotti P (1992) Cognitive rehabilitation of the hemineglect disorder in chronic patients with unilateral brain damage. J Clin Exp Neuropsychol 14:901923. CrossRef Medline

Polich J (2007) Updating P300: an integrative theory of P3a and P3b. Clin Neurophysiol 118:2128-2148. CrossRef Medline

Posner MI, Walker JA, Friedrich FJ, Rafal RD (1984) Effects of parietal injury on covert orienting of attention. J Neuroscience 4:1863-1874. Medline

Praamstra P, Boutsen L, Humphreys GW (2005) Frontoparietal control of spatial attention and motor intention in human EEG. J Neurophysiol 94:764-774. CrossRef Medline

Rastelli F, Tallon-Baudry C, Migliaccio R, Toba MN, Ducorps A, PradatDiehl P, Duret C, Dubois B, Valero-Cabré A, Bartolomeo P (2013) Neural dynamics of neglected targets in patients with right hemisphere damage. Cortex 49:1989-1996. CrossRef Medline

Rengachary J, He BJ, Shulman GL, Corbetta M (2011) A behavioral analysis of spatial neglect and its recovery after stroke. Front Hum Neurosci 5:29. CrossRef Medline

Rorden C, Karnath HO, Bonilha L (2007) Improving lesion-symptom mapping. J Cogn Neurosci 19:1081-1088. CrossRef Medline

Saevarsson S, Kristjánsson Á, Bach M, Heinrich SP (2012) P300 in neglect. Clin Neurophysiol 123:496-506. CrossRef Medline

Schneider W, Eschman A, Zuccolotto A (2002) E-prime: user's guide. Pittsburgh, PA: Psychology Software Tools.

Seiss E, Driver J, Eimer M (2009) Effects of attentional filtering demands on preparatory ERPs elicited in a spatial cueing task. Clin Neurophysiol 120: 1087-1095. CrossRef Medline

Sheskin DJ (2003) Handbook of parametric and nonparametric statistical procedures. London, England: Chapman and Hall; CRC; Taylor and Francis.

Shulman GL, Astafiev SV, Franke D, Pope DL, Snyder AZ, McAvoy MP, Corbetta M (2009) Interaction of stimulus-driven reorienting and expectation in ventral and dorsal frontoparietal and basal ganglia-cortical networks. J Neurosci 29:4392-4407. CrossRef Medline

Silvetti M, Lasaponara S, Lecce F, Dragone A, Macaluso E, Doricchi F (2016) The response of the left ventral attentional system to invalid targets and its implication for the spatial neglect syndrome: a multivariate fMRI investigation. Cereb Cortex 26:4551-4562. CrossRef Medline

Slagter HA, Prinssen S, Reteig LC, Mazaheri A (2016) Facilitation and inhibition in attention: functional dissociation of pre-stimulus alpha activity, P1, and N1 components. Neuroimage 125:25-35. CrossRef Medline

Sturm W, Thimm M, Küst J, Karbe H, Fink GR (2006) Alertness-training in neglect: behavioral and imaging results. Restor Neurol Neurosci 24:371384. Medline

Thiebaut de Schotten M, Ffytche DH, Bizzi A, Dell'Acqua F, Allin M, Walshe M, Murray R, Williams SC, Murphy DG, Catani M (2011) Atlasing location, asymmetry and inter-subject variability of white matter tracts in the human brain with MR diffusion tractography. Neuroimage 54:49-59. CrossRef Medline

Thiebaut de Schotten M, Tomaiuolo F, Aiello M, Merola S, Silvetti M, Lecce F, Bartolomeo P, Doricchi F (2014) Damage to white matter pathways in subacute and chronic spatial neglect: a group study and 2 single-case studies with complete virtual "in vivo" tractography dissection. Cereb Cortex 24:691-706. CrossRef Medline

Thiebaut de Schotten M, Urbanski M, Duffau H, Volle E, Lévy R, Dubois B, 
Bartolomeo P (2005) Direct evidence for a parietal-frontal pathway subserving spatial awareness in humans. Science 309:2226-2228. CrossRef Medline

Thimm M, Fink GR, Küst J, Karbe H, Sturm W (2006) Impact of alertness training on spatial neglect: a behavioural and fMRI study. Neuropsychologia 44:1230-1246. CrossRef Medline

Thimm M, Fink GR, Sturm W (2008) Neural correlates of recovery from acute hemispatial neglect. Restor Neurol Neurosci 26:481-492. Medline

Van Velzen J, Eardley AF, Forster B, Eimer M (2006) Shifts of attention in the early blind: an ERP study of attentional control processes in the absence of visual spatial information. Neuropsychologia 44:2533-2546. CrossRef Medline
Van Velzen JV, Eimer M (2003) Early posterior ERP components do not reflect the control of attentional shifts toward expected peripheral events. Psychophysiology 40:827-831. CrossRef

Verdon V, Schwartz S, Lovblad KO, Hauert CA, Vuilleumier P (2010) Neuroanatomy of hemispatial neglect and its functional components: a study using voxel-based lesion-symptom mapping. Brain 133:880-894. CrossRef Medline

Verleger R, Heide W, Butt C, Wascher E, Kömpf D (1996) On-line brain potential correlates of right parietal patients' attentional deficit. Electroencephalogr Clin Neurophysiol 99:444-457. CrossRef Medline

Vuilleumier P, Hester D, Assal G, Regli F (1996) Unilateral spatial neglect recovery after sequential strokes. Neurology 46:184-189. CrossRef Medline 